\title{
Poleward Deflection of Storm Tracks
}

\author{
ISIDORO ORLANSKI \\ Geophysical Fluid Dynamics Laboratory/NOAA, Princeton University, Princeton, New Jersey
}

(Manuscript received 20 February 1997, in final form 18 November 1997)

\section{ABSTRACT}

\begin{abstract}
An analysis of 11 years of European Centre for Medium-Range Weather Forecasts data focuses primarily on the vertically averaged high-frequency transients. The conclusions are discussed in the context of (a) the winter storm track, (b) monthly variability, and (c) interannual variability. (a) Winter storm track: Results show that the pattern of the forcing by the high-frequency eddies along the storm track is highly correlated with the stationary circulation, and the forcing itself is primarily responsible for the location of the trough-ridge system associated with the stationary flow. The results also clarify the role of wind component covariance terms $\overline{u^{\prime} v^{\prime}}$ and $\left(\overline{v^{\prime 2}}-\overline{u^{\prime 2}}\right)$ in the column-averaged vorticity forcing. The simpler term $\overline{u^{\prime} v^{\prime}}$ has the well-known effect of intensifying the anticyclonic (cyclonic) tendencies on the southern (northern) side of the jet, thereby producing an increase in the barotropic component of the zonal jet. The $\left(\overline{v^{\prime 2}}-\overline{u^{\prime 2}}\right)$ term displays a quadrupole pattern, which is also approximately in phase with the trough-ridge system associated with the stationary flow. (b) Monthly variability: Eddy activity has been shown to possess a seasonal life cycle, increasing during the early fall and reaching a maximum around the month of November, then decaying for most of the winter months. Month-to-month variations in eddy activity over the Pacific Ocean show that energy levels increase up through November, decreasing thereafter, at the same time the trough-ridge circulation pattern is intensifying. By December, baroclinicity in the western Pacific has increased substantially, and low-level eddies are found to break by the middle of the ocean. Upper-level eddies start to break well before reaching the west coast of North America, resulting in a displacement of the maximum in $\left(\overline{v^{\prime 2}}-\overline{u^{\prime 2}}\right)$ westward from its November position and increasing the trough-ridge forcing by the high-frequency eddies. (c) Interannual variability: Wintertime eddy kinetic energy is seen to extend further eastward through the Pacific Ocean during the warm phase but displays an abrupt termination during the cold phase. Anomalies in the eddy transient forcing tend to be quite similar to that of the Pacific-North American pattern itself. The extension of the storm track during the warm phase resembles that of fall conditions and is present in the winter season because the source of low-level baroclinicity is extended well into the eastern Pacific for this El Niño-Southern Oscillation phase.
\end{abstract}

\section{Introduction}

Considerable progress has been made over the past decade in understanding the general circulation of the atmosphere, particularly with regard to the behavior and characteristics of large-scale eddies and their interaction with the mean flow. One technique that has proven useful in obtaining insight into the role of eddies has been the separation of processes into high- and low-frequency components. In particular the existence, shape, and other characteristics of storm tracks have been found to be intimately related to the configuration of the time-mean circulation (Blackmon et al. 1977, Blackmon et al. 1984; Lau and Holopainen 1984; Hoskins et al. 1982; Hoskins and Valdes 1990; Held et al. 1989). The Pacific and Atlantic storm tracks originate in the vicinity of the stationary troughs over the western part of the respective oceans and terminate near the stationary ridges over the

Corresponding author address: Dr. Isidoro Orlanski, NOAA/ GFDL, Princeton University, P.O. Box 308, Princeton, NJ 08542. E-mail: io@gfdl.gov west coast of North America and over Europe. It has been also noted in these studies that the storm tracks lie downstream and slightly poleward of the vertical and horizontal shear zone associated with the quasi-permanent jet streams over Japan and over the east coast of North America.

Hoskins and Valdes (1990) discussed the steady response of the atmosphere to forcing by eddy heat fluxes, eddy momentum fluxes, and diabatic heating. Using a model linearized about the zonal flow, they suggested that diabatic heating is essential in maintaining the high baroclinicity in the vicinity of the storm track and is essential to the maintenance of the storm track. Furthermore, they speculated that since the diabatic heating over the storm track is caused by horizontal and vertical displacements associated with individual storms, it could be concluded that storm tracks are self-maintaining.

More recently, Chang and Orlanski (1993) offered a complementary explanation for the observed distribution of eddy activity downstream of the strong baroclinic regions that characterize the western oceans. Using an idealized numerical model, they showed that small am- 
plitude eddies introduced into the baroclinic regions at the entrance to the storm track grew by baroclinic processes, but did not initially affect the baroclinic zone. Farther downstream, however, the eddies became strong enough for their heat fluxes to reduce the low-level baroclinicity. The net result was a distribution of baroclinicity along the storm track, which is characterized by large values at the entrance of the storm track and weaker values downstream, similar to that in the observed oceanic storm tracks. Yet, despite the reduced baroclinicity in the middle of the storm track, eddies could attain large amplitudes by virtue of energy fluxes from eddies upstream. With this mechanism, a complete picture of the evolution of eddies along the storm track could be described. The land-sea contrast off the east coast of the Asian and North American continents results in diabatic heating by the warm ocean and, in turn, enhanced baroclinicity conducive to the generation of baroclinic eddies. As these eddies complete their life cycle, they flux energy downstream to new eddies, which, as a consequence, require less baroclinicity in order to grow to significant amplitude. These fluxes are also directed upward, producing eddies that are deeper than those close to the entrance of the storm tracks. These results are in complete agreement with the description by Hoskins et al. (1983) derived from an analysis of one winter using European Centre for Medium-Range Weather Forecasts (ECMWF) data.

This description gives a clear picture of the evolution of eddies along the entrance and middle portion of the storm track. However, a far less clear picture exists at the termination of the storm tracks. Observational and diagnostic studies of the linear response of the stationary circulation have shown that the observed ridges in the eastern oceans are one possible cause of the blocking and termination of the eddy activity there (Lau 1988). In fact, a number of studies have suggested that eddies can reinforce blocking flow patterns (Shutts 1983; Illari and Marshall 1983; Illari 1984). Experiments with a nonlinear barotropic vorticity equation done by Shutts (1983) show that dipole blocking patterns can be created by the action of the eddies. He concluded that eddies alone are responsible for the block since the time-mean vorticity equation had no external forcing functions such as an orographic term. Furthermore, the time-mean anticyclonic eddy vorticity forcing was located just upstream of the "blocking high" in agreement with data analyzed by Illari (1984) for the anomalous circulation over Europe of 1976. More recently, a number of idealized mean flow studies have found that the eddies tend to decay due to the strong deformation at the exit of the mean jet (Witaker and Dole 1995; Mak and Cai 1989). Linear simulations of baroclinic development with basic climatological states performed by Branstator (1995) suggest a consistency between the diffluence area of the jet and the reduction of eddy activity. Yet, the reason that ridges are found at the end of storm tracks is more difficult to find. What is clear is that wherever the storm tracks end, a ridge can be found. It also seems clear from idealized model simulations that this ridge is associated with the diffluence of the zonal jet stream and this diffluence strains the eddies and contributes to their decay.

Held et al. (1989) found-in examining the stationary linear response forced by ororgraphy, transients, and diabatic heating obtained from GCM simulations-that the western mountains of North America and transients seem equally responsible for the ridge formation at the terminus of the Pacific storm track. The transients appeared to produce positive height tendencies over the eastern Pacific, while orography produced a maximum over western North America. However, the ridge over the eastern Atlantic was not well simulated, leaving the authors to speculate that the GCM storm track was weaker than observations and suggesting that transient eddy forcing could be even more important than their results suggest.

Lau and Nath (1991) addressed the question of highfrequency forcing of the stationary component. They found a major trough over the central Pacific and a rather weaker high over northwestern North America, which extended to the eastern and south central Pacific Ocean. Their analysis also suggested that the high-frequency transients produced significant negative height tendencies over the western and central Atlantic and small positive tendencies over the eastern Atlantic.

In the present study, we will try to elucidate from an analysis of atmospheric data the relationship between the poleward deflection of the storm track axis and the evolution of the ridge at the end of storm tracks. Highfrequency forcing will be analyzed without resorting to any other large-scale filtering. The emphasis will be on describing the seasonal and interannual variability of this forcing and assessing whether the storm track is self-limiting by virtue of its tendency to produce a poleward deflection. Because of the tendency for eddies to flux energy upward and grow deeper downstream of the strong baroclinic zone, their poleward momentum flux tends to shift the westerlies northward. The poleward momentum flux tendencies and/or the fact that as eddies break they could enhance blocking highs downstream may cause a series of eddies along the storm track to follow a progressively more poleward path, and the whole storm track will be deflected to higher latitudes. This picture, in which the eddies themselves produce the poleward deflection, is certainly consistent with the large cyclonic tendencies produced by the transients in the middle of the storm track, forcing the trajectories of the surface lows at its termination well poleward of the central storm track, as in the case of the Aleutian and the Icelandic lows. The relation of the observed quasi-stationary trough-ridge system in phase with the entrance and termination of the storm track will be discussed.

The high-frequency transient forcing for the vertically averaged mean vorticity analysis for the winter circu- 
lation will be presented in section 2, and will confirm and support previous work by Lau (1988), Holopainen et al. (1982), and Hoskins et al. (1983) using different data. In section 3, the monthly variability of the eddy statistics will be discussed. The statistics of the two phases of the El Niño-Southern Oscillation (ENSO) cycle will be presented in section 4 , with the summary and conclusions in section 5 .

\section{The winter season}

\section{a. Dataset and analysis procedure}

The dataset for this study consists of twice daily temperature, wind, and heights for seven pressure levels (1000, 850, 700, 500, 300, 200, and $100 \mathrm{mb}$ ), from ECMWF data for 1980-90. The analysis approach is similar to that used in previous studies (Lau 1988; Lau and Nath 1991). In particular, the technique used by Chang (1993) is adopted, in which only disturbances with synoptic timescales are retained. Two 41-point high-pass time filters with half-power points around 6 and 12 days, respectively, were examined (see appendix). The results shown here are for eddies derived using the 12-day high-pass filter.

\section{b. Eddy characteristics for the winter}

The time-mean December-February 500-mb height for the 11 years of data is shown in Fig. 1a, together with the corresponding vertically averaged (200-850 $\mathrm{mb}$ ) eddy kinetic energy. The Atlantic and Pacific storm tracks are readily apparent, as are the troughs and ridges at the entrance and exit regions of each. The focus for the current investigation will be the Pacific storm track, in which the initial eddies are generated by baroclinic processes in the western Pacific. Eddies forming though the middle of the storm track do not require the same level of baroclinicity because much of the energy is derived from the convergence of fluxes from decaying eddies upstream. Chang (1993) used a time-lag regression analysis to show a clear picture of this evolution of eddies in the middle of the storm track.

At the exit region of the storm track in the eastern Pacific, the situation is quite different. An analysis of a $10^{\circ}$ lat band, similar to that used by Chang (1993), is summarized in Fig. 2, and reveals progressive eddies upstream of $140^{\circ} \mathrm{W}$, but weaker and more stationary eddies east of $140^{\circ} \mathrm{W}$, in the vicinity of the ridge displayed in Fig. 1a. One simple explanation is that this ridge "blocks" the propagation of the eddies. Another possible explanation is that the eddies decay as a consequence of the strong diffluence in the vicinity of the ridge. In all likelihood, both processes are important, with some eddies tracking northward over the ridge and some eddies undergoing decay. It should be noted that the apparent extended lifetime of the eddies near the ridge could be contributing to the "stationary" circu- lation itself, the eddies may appear stationary only because their eastward velocity decreases as they move poleward over the ridge. However, it will be shown that the eddies are indeed supporting the stationary circulation.

What is important, then, is what controls the intensity of the eastern Pacific ridge (hereafter, EPR), given the role it plays in the midlatitude winter circulation. A weaker EPR permits midlatitude synoptic systems easier entrance to the west coast of North America, at a latitude close to the axis of the storm track. One specific case where this happens is during the warm phase of the ENSO cycle. During El Niño years, the ridge is weaker and the storm track lengthens toward the west coast of the United States, whereas during La Niña years, the ridge is stronger and storms are more commonly deflected poleward into northern Canada and Alaska. The following sections present an analysis of the role of transient eddies in the forcing of the stationary circulation.

\section{c. Vertically averaged vorticity equation}

The focus of this study is the large-scale circulation that could arise from the high-frequency (HF) forcing of the storm track. This circulation has a large projection onto the vertically averaged flow so that a vertically integrated analysis will suffice. Conservation of pseudopotential vorticity (PV) in quasigeostrophic theory has an attractive simplicity that has stimulated a large number of studies (Holopainen and Oort 1982a,b; Holopainen et al. 1982; Lau and Nath 1991). But, as pointed out by Hoskins (1983), quasigeostrophic PV analysis is limited by the assumption of constant static stability, which breaks down over synoptic scales, and by the arbitrariness of fixing a specific latitude to determine the coriolis parameter $\mathrm{f}_{0}$. Here we will avoid placing such constraints on the analysis.

Let us then consider a vertical averaged statistic that will be useful in analyzing the vorticity budget. The time-mean vorticity equation is

$$
\begin{aligned}
\bar{D} \bar{\zeta}= & (-\beta \bar{v})+(f+\bar{\zeta}) \frac{\partial}{\partial p} \bar{\omega}-\left(\mathbf{k} \cdot \boldsymbol{\nabla} \times \overline{\boldsymbol{F}}_{h f}\right) \\
& +\mathbf{k} \cdot \boldsymbol{\nabla} \times \overline{\mathfrak{R}}+V,
\end{aligned}
$$

where the $\bar{D}=(\bar{u} / a \cos \phi)(\partial / \partial \lambda)+(\bar{v} / a)(\partial / \partial \phi), \bar{\zeta}$ is the time-averaged vertical component of the relative vorticity, $\beta$ is the meridional derivative of the Coriolis parameter, $\mathfrak{R}$ is the frictional dissipation, $V$ represents the vertical advection of mean vorticity and convergence of the HF vertical vorticity fluxes. The term $\overline{\mathbf{F}}_{h f}$ is the high-frequency forcing and is given by

$$
\overline{\mathbf{F}}_{h f}=\frac{1}{a \cos \phi}\left(\begin{array}{l}
\frac{\partial}{\partial \lambda} \overline{u^{\prime} u^{\prime}}+\frac{\partial}{\partial \phi} \overline{u^{\prime} v^{\prime}} \cos \phi \\
\frac{\partial}{\partial \lambda} \overline{u^{\prime} v^{\prime}}+\frac{\partial}{\partial \phi} \overline{v^{\prime} v^{\prime}} \cos \phi
\end{array}\right)+\left(\begin{array}{l}
\overline{\frac{u^{\prime} v^{\prime}}{a}} \tan \phi \\
\frac{u^{\prime} u^{\prime}}{a} \tan \phi
\end{array}\right) .
$$


Vertically Averaged Eddy Kinetic Energy and 500mb Heights DJF 1980-1990

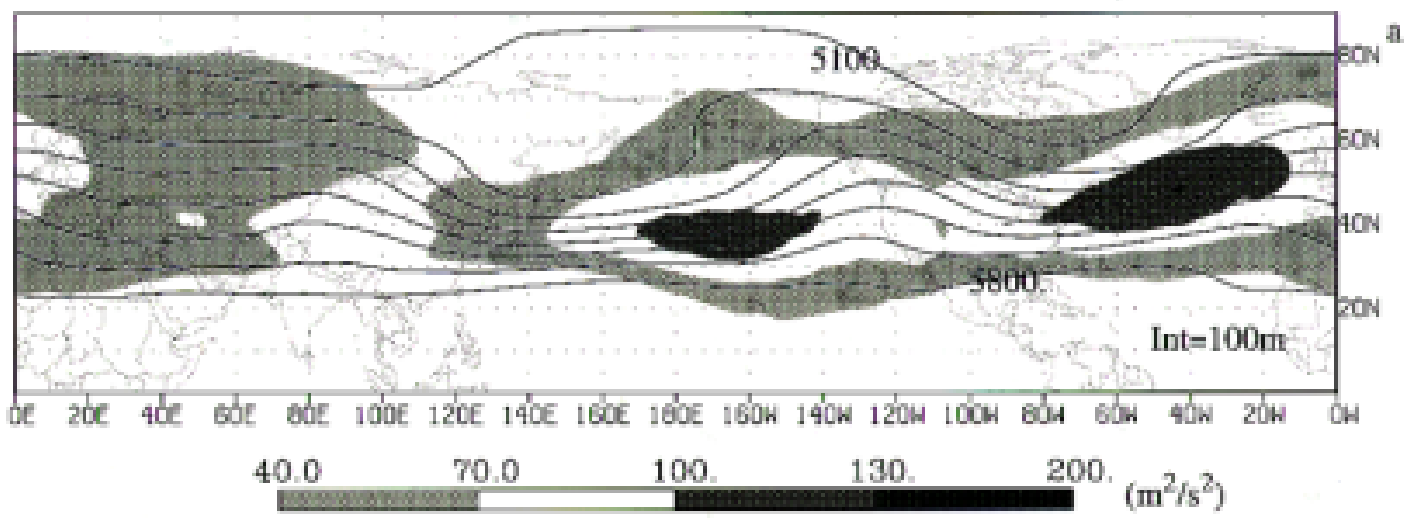

Stream Function Tendency from Eddy Forcing and 500mb Heights DJF 1980-1990

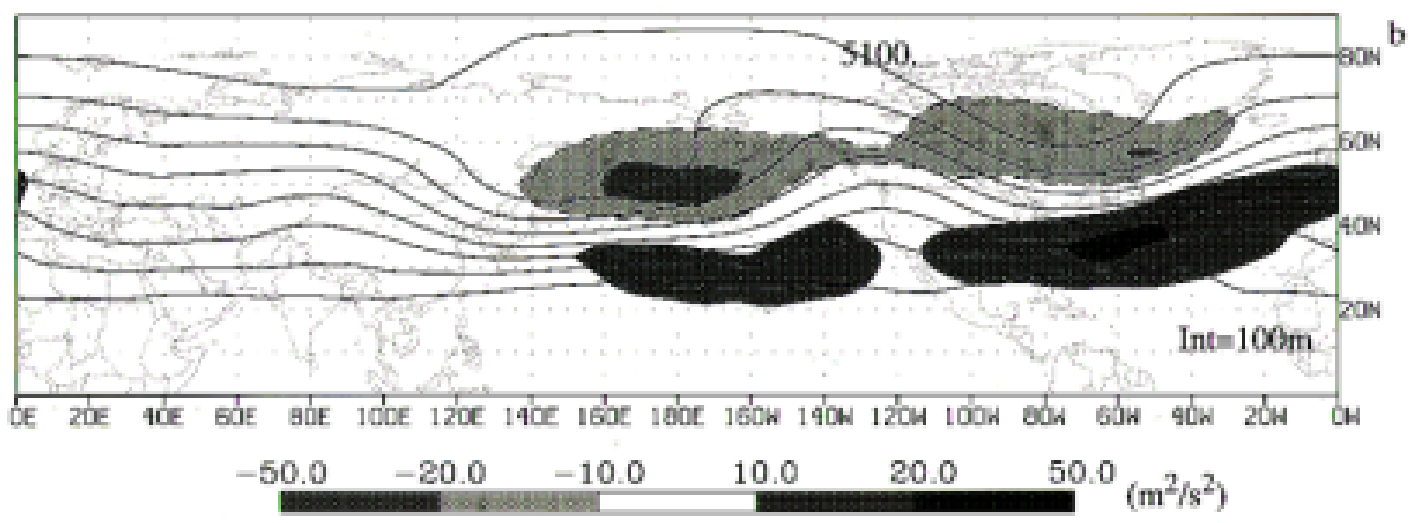

Stream Function Tendency and 500mb Heights (Deviations of zonal mean) DJF 1980-1990

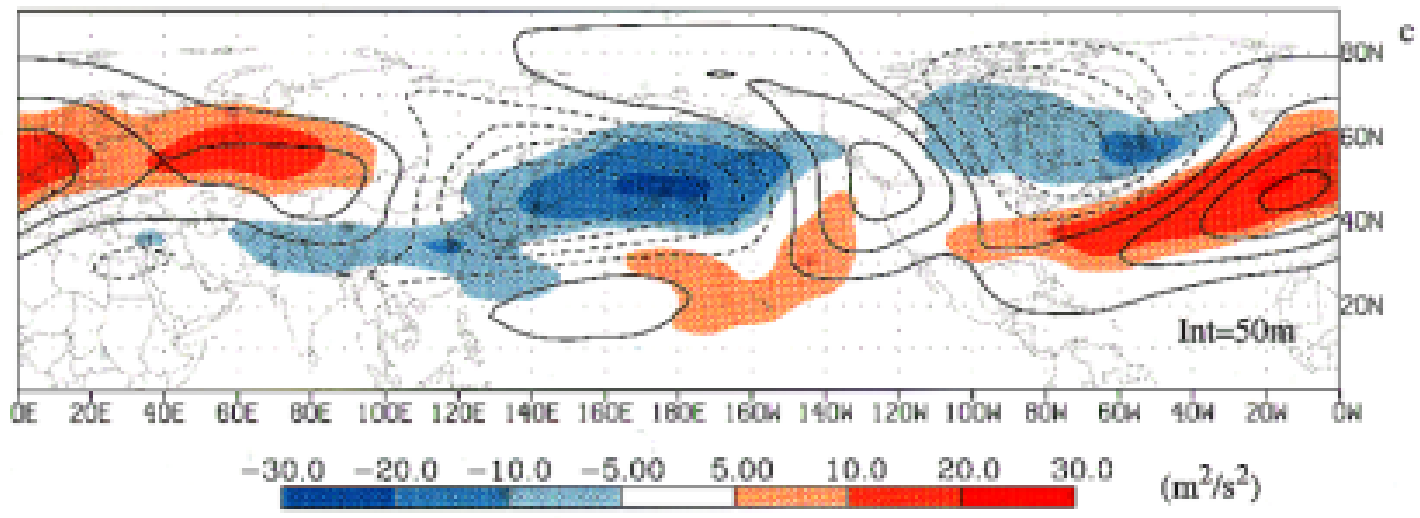

FIG. 1. (a) Mean 500-mb goepotential height and vertically averaged transient (12-day filter) eddy kinetic energy (shaded) for the winter months of December-February for the period 1980-90. (b) Mean 500-mb goepotential height (contours) and the streamfunction tendency from the vertically averaged transient forcing for the same period. For an estimate of the intensity for the streamfunction tendency, a difference of $10 \mathrm{~m}^{2} \mathrm{~s}^{-2}$ in $10^{\circ}$ lat corresponds to a wind acceleration of $0.85 \mathrm{~m} \mathrm{~s}^{-1}$ day $^{-1}$. (c) The deviation of zonal mean for the fields shown in (b). 


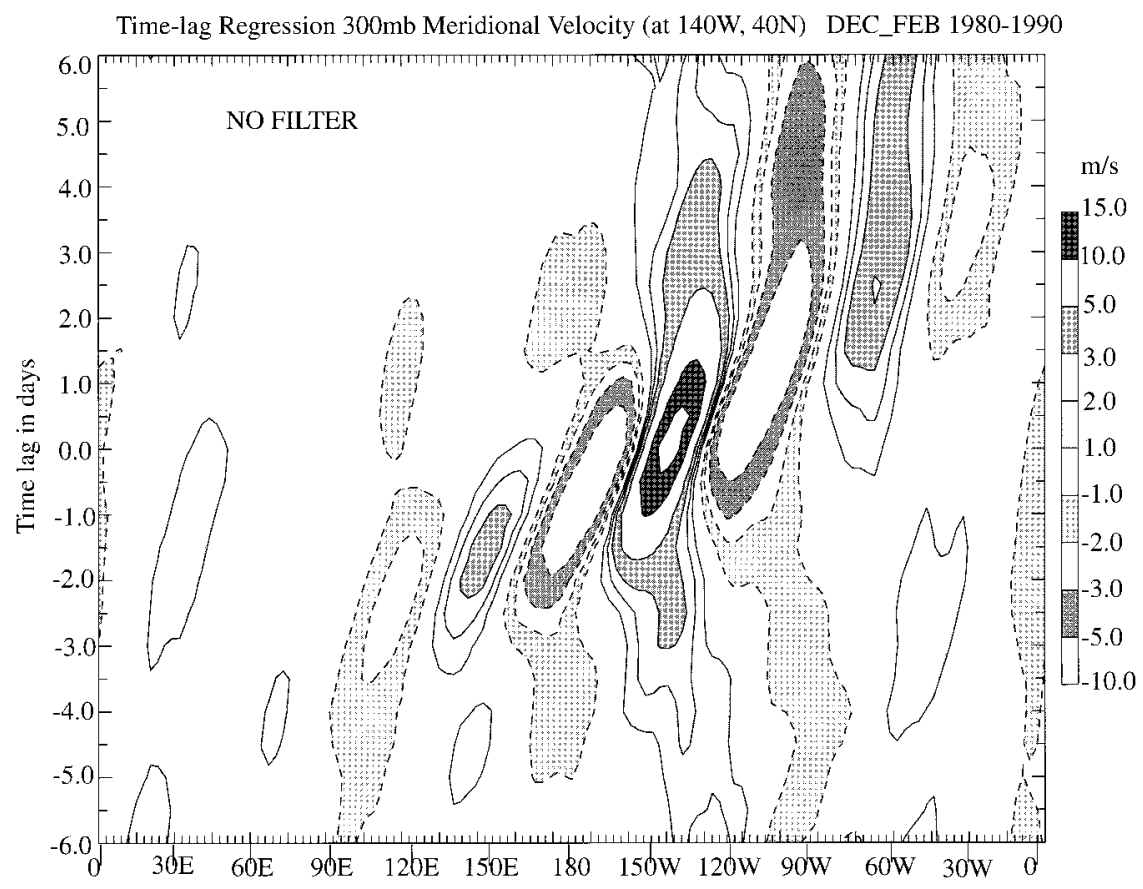

FIG. 2. Time lag regression of 300-mb meridional velocity for the months of December-February for the period $1980-90$. The location of the test function is at $140^{\circ} \mathrm{W}$ and is an average over a $10^{\circ}$ band centered at $40^{\circ} \mathrm{N}$; this is approximately the mean location of the stationary eastern Pacific ridge.

The vorticity equation (2.1) and the forcing (2.2) are similar to that derived by Holopainen et al. (1982). The vertical integral of (2.1) can be expressed as

$$
\begin{aligned}
& \int_{p_{0}}^{p_{T}}(\bar{D} \bar{\zeta}+\beta \bar{v}) d p \\
& \quad \approx \int_{p_{0}}^{p_{T}}\left(-\mathbf{k} \cdot \boldsymbol{\nabla} \times \overline{\mathbf{F}}_{h f}+\mathbf{k} \cdot \boldsymbol{\nabla} \times \bar{\Re}\right) d p .
\end{aligned}
$$

Note that in (2.3) the tendency of the vorticity vertically integrated from an upper pressure $p_{T}$ to the surface $p_{0}$ does not include the stretching term $f_{0}\left(\omega_{T}-\omega_{0}\right) /\left(p_{T}\right.$ $\left.-p_{0}\right)$. The thickness change $\left(\omega_{T}-\omega_{0}\right)$ is given in the quasigeostrophic framework by the thermodynamic energy equation at the corresponding boundary pressures $p_{T}$ and $p_{0}$ [see Holton 1992, his Eq. (6.13)]. Although under particular conditions this tendency could be significant, in the time-averaged budgets this is assumed to be small, and it has been neglected in previous studies (e.g., Lau and Nath 1991). This assumption implies that the heat fluxes can redistribute vorticity but will not affect its column integral. Generally, the stretching forced by heat fluxes will produce vorticity of one sign at low levels and the opposite sign at the upper levels (see Lau and Nath 1991). Neglecting the integrated stretching term removes the need for the heat budget calculation at the lower boundary $(1000 \mathrm{mb})$, which could be of questionable accuracy.

The individual terms on the left of (2.3) are relatively large but for the most part cancel each other (Lau 1979), as absolute vorticity contours tend to parallel time-mean streamlines. The last term on the right of Eq. (2.3), namely, the vertical integral of the curl of the frictional forces, roughly balances the curl of the surface wind stresses. Consequently, the vertical integral of the curl of high-frequency forcing roughly balances the curl of the total wind stress at the surface (Holopainen and Oort 1981a).

The curl of the forcing term, $\overline{\mathbf{F}}_{\mathrm{hf}}$, in Eq. (2.3) can be expressed as

$$
\begin{aligned}
\left(-\mathbf{k} \cdot \boldsymbol{\nabla} \times \hat{\overline{\mathbf{F}}}_{\mathrm{hf}}\right) & \\
= & -\left(\frac{1}{a \cos \phi}\right)^{2} \frac{\partial}{\partial \phi} \frac{\partial}{\partial \lambda}\left(\widehat{\widehat{v^{\prime} v^{\prime}}}-\widehat{\widehat{u^{\prime} u^{\prime}}}\right) \cos \phi \\
& +\frac{1}{a^{2} \cos \phi}\left(\frac{\partial}{\partial \phi} \frac{1}{\cos \phi} \frac{\partial(\cos \phi)^{2}}{\partial \phi}-\frac{1}{\cos \phi} \frac{\partial^{2}}{\partial \lambda^{2}}\right)\left(\widehat{u^{\prime} u^{\prime}}\right),
\end{aligned}
$$

where the vertical average of a quantity, $Q$, is defined as

$$
\hat{Q}=\frac{1}{\left(p_{T}-p_{0}\right)} \int_{p_{0}}^{p_{T}} Q d p .
$$

Equation (2.4) is similar to that derived by Lau (1988) in calculating geopotential height tendencies. As in their presentation, the eddy forcing can be represented as the 
induced tendency of the vertically averaged streamfunction $\psi_{\tau}$, here expressed as

$$
\psi_{\tau}=\nabla^{-2}\left(-\mathbf{k} \cdot \boldsymbol{\nabla} \times \overline{\mathbf{F}}_{\mathrm{hf}}\right) .
$$

This approach is sometimes used to filter small-scale noise from the eddy forcing. In this study, however, both the streamfunction tendency and the eddy forcing terms are examined.

Hoskins (1983) provided an extensive discussion of the budget analysis made by Holopainen et al. (1982), Lau (1979), Holopainen and Oort (1981a,b), and Hoskins et al. (1983), with respect to the vorticity equation (2.3). The discussion below closely follows the main conclusions of those studies.

\section{d. High-frequency forcing in the winter circulation}

The 11-yr wintertime mean streamfunction tendency given by Eq. (2.5) is shown in Fig. 1b, corresponding to the circulation depicted in Fig. 1a. Negative tendencies are observed on the northwest side of the storm track, with positive tendencies on the southeast side. Thus, the eddies act to accelerate the westerlies in the middle of the storm track but also deflect them poleward at the exit of the storm track. Figure $1 \mathrm{~b}$ depicts the wintertime 500-mb height and streamfunction tendency due to the vertically averaged high-frequency transient forcing, whereas Fig. 1c shows the deviations from the zonal mean of the same fields as in Fig. 1b to emphasize the phase differences between the streamfunction tendency anomalies and the 500-mb height anomaly. Over the Pacific Ocean, the negative tendencies of the eddy forcing are slightly downstream of the negative 500-mb height, whereas the positive forcing is slightly upstream from the positive height anomaly. We will come back to this point later. The HF eddy forcing shown in Fig. $1 \mathrm{~b}$ is very similar to the high-frequency forcing (2.5-6 days) obtained by Holopainen et al. (1982) for eight winters of twice-daily data produced by the National Centers for Environmental Prediction (NCEP). The eddy vorticity flux and its convergence have been discussed by Hoskins (1983), who examined separately the vorticity induced by the two terms in Eq. (2.4), namely, $\left(\overline{v^{\prime 2}}-\overline{u^{\prime 2}}\right)$ and $\left(\overline{u^{\prime} v^{\prime}}\right)$. It has been argued that, at the end of the storm track, synoptic timescale eddies tend to elongate in the meridional direction. As a consequence, $\overline{v^{\prime 2}}$ is larger than $\overline{u^{\prime 2}}$ and $\left(\overline{v^{\prime 2}}-\overline{u^{\prime 2}}\right)$ attains a maximum at the end of the storm track. As we shall see, $\overline{v^{\prime 2}}$ is larger than $\overline{u^{\prime 2}}$ almost everywhere.

The contributions of these two terms are summarized in the schematic diagram shown in Fig. 3. The meridional momentum flux due to baroclinic waves is depicted in Fig. 3a. The important term for the meridional momentum flux contribution is $\partial^{2}\left(\overline{u^{\prime} v^{\prime}}\right) / \partial \phi^{2}$, so that the induced vorticity is cyclonic on the poleward side of the jet and anticyclonic on the equatorward side, and the streamfunction tendency will have the same sign as the momentum fluxes. Depending on the characteristics

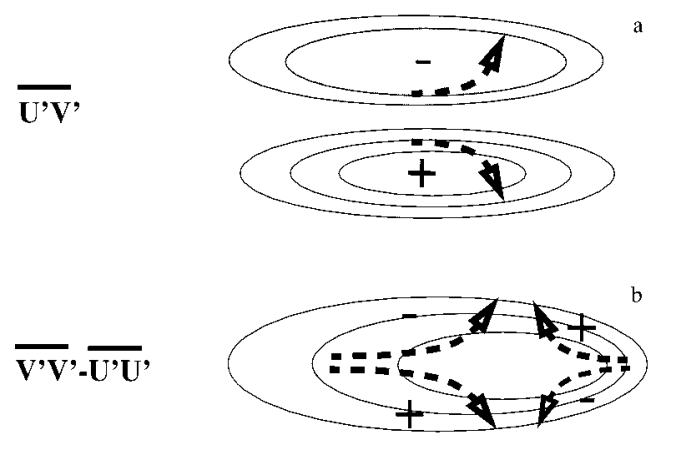

Total

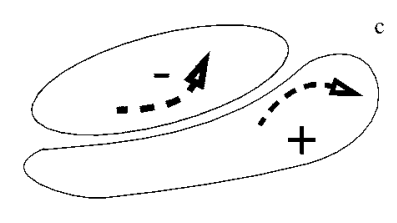

Momentum Fluxes Induced Circulation Sign of the induced Stream Function

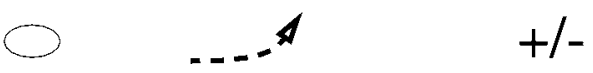

FIG. 3. Schematic of the correlation velocity patterns and the induced circulation and vorticity tendency. (a) The meridional flux of zonal momentum and its dipole circulation. (b) The variance of $v$ velocity minus the variance of the $u$-velocity and its induced quadrupole circulation. The quadrupole is centered at the maximum of the variance difference and is stronger for more highly localized maxima. (c) The total response of the eddy forcing.

of the mean flow and the scale of the eddies, the dipole structure due to the meridional momentum fluxes could be antisymmetric, enhancing the strength of the jet but without displacement of its position, or asymmetric. When the positive part of the forcing is stronger (as in the figure), the jet will be enhanced and displaced poleward. A negative bias will displace the jet equatorward.

The contours of $\left(\overline{v^{\prime 2}}-\overline{u^{\prime 2}}\right)$ in Fig. $3 \mathrm{~b}$ exhibit a maximum close to the termination of the storm track. The term $-(\partial / \partial \phi) \overline{\left(v^{\prime 2}-u^{\prime 2}\right)}$ will be positive/negative in the poleward/equatoward sides of the axis of maximum $\left(\overline{v^{\prime 2}}\right.$ $\left.-\overline{u^{\prime 2}}\right)$. The induced vorticity $(\partial / \partial \lambda)(\partial / \partial \phi) \overline{\left(v^{\prime 2}-u^{\prime 2}\right)}$ will display a quadrupole pattern, as shown by the dashed vectors in Fig. 3b, with anticyclonic tendencies to the northeast and southwest and cyclonic tendencies to the northwest and southeast.

The combined effects of the two terms (as shown in Fig. 3c) is to tilt the storm track axis into a southwestnortheast orientation. This effect is clearly identified in the actual analysis shown in Fig. 1b. To interpret these results, let us assume for simplicity that the eddies are the only forcing (no thermal or orographic) in a zonalmean flow. Following Eq. (2.3), the expected response would be a trough downstream of the storm track entrance (compensated by eastward vorticity advection) 


\section{Stream Function Tendency and Individual Contributions ～DJF 1980-1990}
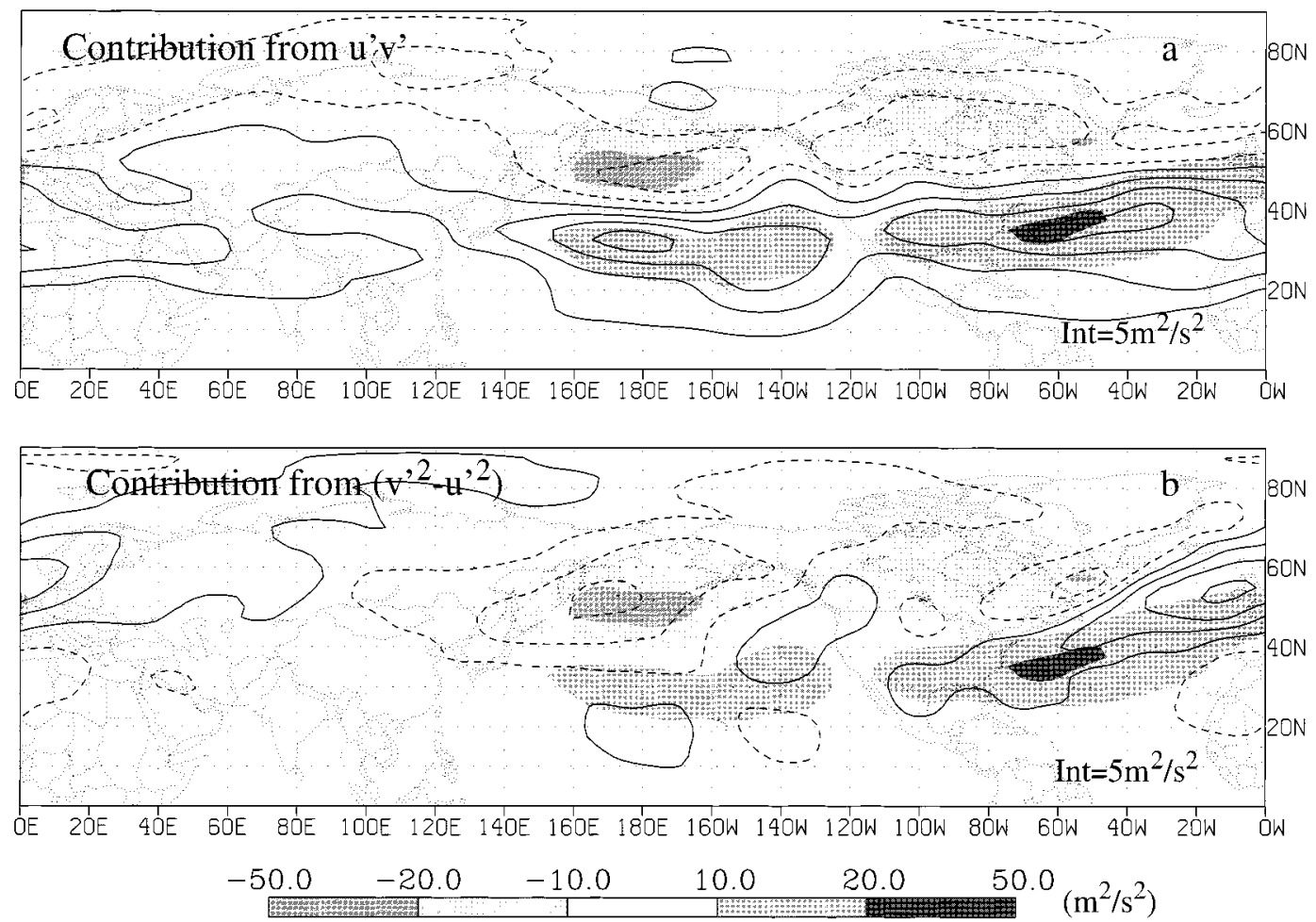

FIG. 4. Contours of the individual contributions to the streamfunction tendencies from (a) $\overline{u^{\prime} v^{\prime}}$ and (b) $\overline{v^{\prime 2}}-\overline{u^{\prime 2}}$, for the DecemberFebruary mean over the period 1980-90. The total streamfunction tendency from Fig. 1b is also shown as shaded bands for reference.

and a ridge slightly east of the termination. It is clearly shown in Fig. 1c that the position of the positive height anomaly is consistent with the eddy forcing, in a manner similar to the proposed mechanism for enhancing the blocking high (Shutts 1983; Illari and Marshall 1983; Illari 1984). However, the fact that the center of the low anomaly is slightly west of the HF forcing suggests that other forcing (land cooling, the Tibetan Plateau, etc.) could be primarily responsible for the western trough, and the eddy forcing only enhanced and extended eastward the existing trough.

The contributions to the streamfunction tendency from the meridional momentum flux $\overline{u^{\prime} v^{\prime}}$ and from $\left(\overline{v^{\prime 2}}\right.$ $-\overline{u^{\prime 2}}$ ) for the winter circulation are shown in Fig. 4. The streamfunction tendency (from Fig. 1b) is shown as a shaded band for reference. In the Pacific, the $\overline{u^{\prime} v^{\prime}}$ term displays large contributions to each side of the storm track, consistent with Fig. 3a. This acts primarily to intensify the westerly jet, enhancing the anticyclonic shear to the south and the cyclonic shear to the north. The $\left(\overline{v^{\prime 2}}-\overline{u^{\prime 2}}\right)$ term displays the quadrupole signature shown in Fig. 3b, primarily because of the presence of the maximum $\left(\overline{v^{\prime 2}}-\overline{u^{\prime 2}}\right)$ in the eastern half of the storm track. Notice that whereas the anticyclonic forcing is mainly due to the contribution of $\overline{u^{\prime} v^{\prime}}$, both terms contribute to the cyclonic forcing on the northern side of the storm track, although the contribution from $\left(\overline{v^{\prime 2}}-\right.$ $\left.\overline{u^{\prime 2}}\right)$ is slightly larger. The anticyclonic forcing due to $\left(\overline{v^{\prime 2}}-\overline{u^{\prime 2}}\right)$ has the effect of deflecting the axis of the storm track poleward.

In the Atlantic storm track, the contribution from $\left(\overline{v^{\prime 2}}\right.$ $\left.-\overline{u^{\prime 2}}\right)$ is predominantly positive and much larger in magnitude than in the Pacific, forcing the entire storm track axis more strongly into a southwest-northeast orientation. While there are clear quantitative differences between the storm tracks, the shape still possesses a quadrupole character, as the strong positive contributions are flanked to the northwest and southeast by cyclonic contributions, albeit weak. At first glance one may suspect that the northeast tilting of this contribution may be due to the fact that the storm track itself has a similar tilting as $\left(\overline{v^{\prime 2}}-\overline{u^{\prime 2}}\right)$. Such tilting by itself could have explained the enhanced anticyclonic tendencies to the northeast but equally would have enhanced the cyclonic tendencies over the southwest as well (as in Fig. $3 b$ ); the opposite of this is displayed in Fig. 4b. It should be added that the structure of $\overline{u^{\prime} v^{\prime}}$ does not depend very much on the form of the decaying eddies. In fact, a similar poleward flux of westerly momentum has been shown in the evolution of baroclinic normal modes (Simmons and Hoskins 1976). However, whether the eddies decay reversibly as in downstream development, fluxing energy downstream to a new eddy of the same or slightly larger horizontal scale, or irreversibly 


\section{Curl of Surface Drag ( $\rho$ CdlVs/Vs) at $1000 \mathrm{mb} \quad$ DJF 1980-1990}
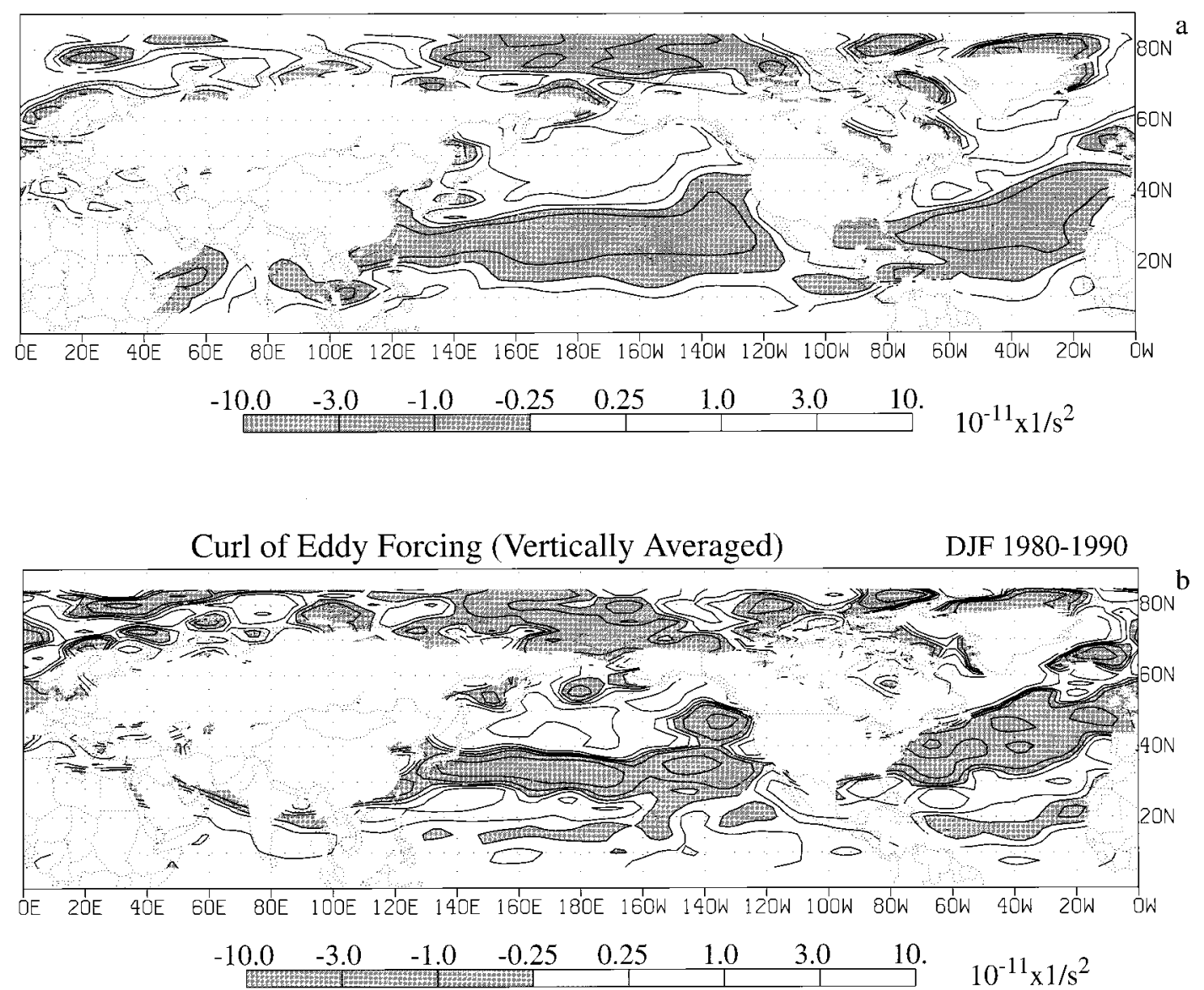

FIG. 5. (a) Curl of the 1000-mb surface wind drag normalized by the column pressure drop $(900 \mathrm{mb})$. (b) Curl of the vertically averaged eddy forcing.

through enstrophy cascade (e.g., by wave breaking), could strongly influence the structure along the storm track of $\left(\overline{v^{\prime 2}}-\overline{u^{\prime 2}}\right)$ and consequently its contribution to the streamfunction tendencies. We will address this point later when discussion of the seasonal variability is presented.

As mentioned earlier, the eddy forcing is partially balanced by frictional forces. While we cannot accurately calculate the total vorticity budget, it can be shown that the two terms on the rhs of (2.3) roughly balance, with the vertical integral of the curl of highfrequency forcing balanced in part by the curl of the wind stresses at the surface, as shown in the pioneering work by Holopainen and Oort (1981a). They estimated the zonal average of the curl of high-frequency forcing over the Pacific basin and showed a close agreement with the curl of the wind stress at the surface. Figure 5 shows the curl of the surface drag and the curl of the vertically averaged eddy forcing. It should be pointed out that two simplifications are limiting the accuracy of the wind stress calculation shown in Fig. 5a. First, since the ECMWF data do not include surface wind, the 1000- $\mathrm{mb}$ winds have been used. These wind data are very similar to the global ocean wind stress climatology used by Trenberth et al. (1989). Second, because of the lack of boundary layer values, it was decided to use a constant value of $C_{\mathrm{d}}=1 \times 10^{-3}$ in the calculation of the surface drag. Although the drag coefficient $C_{\mathrm{d}}$ in the wind stress formulation $\boldsymbol{\tau}=\rho C_{d}|\boldsymbol{V}| \boldsymbol{V}$ is a function of the stability characteristics of the constant flux layer and the roughness height $z_{0}$ over the ocean surfaces, and can vary between 1.5 to $0.7 \times 10^{-3}$ (Orlanski et al. 1991, for details), the constant $C_{d}$ value is expected to give an acceptable qualitative pattern. Figure 5a shows the distribution of the curl of the total (no time filter) wind stresses, which is very similar to that calculated by Trenberth et al. (1989) (note, the amplitude here has been scaled by the integrated pressure of the air column). Figure $5 \mathrm{~b}$ shows the vertically averaged eddy forcing for the winter season, which displays qualitative similarities, at least over the Pacific Ocean, with the curl of the wind stresses. However, the amplitude of the eddy forcing is about twice that of the curl of the wind stresses and the spatial distribution over the Pacific is more in 
phase than over the Atlantic Ocean. Probably the stationary component may have contributed more to the wind stress over the Atlantic Ocean. It is interesting to note that this difference is also present in the early estimates by Holopainen and Oort (1981a) using NMC (now NCEP) data-not only is the amplitude of the eddy forcing larger than the total wind stress but the latitude where the curl changes sign is slightly farther north for the eddy forcing than for the wind stress. The zonal variability of the two terms appears quite similar, although the eddy forcing (Fig. 5b) has considerably more high wavenumber amplitude than its streamfunction response in Fig. 1b. The larger features as well as the poleward extent of the anticyclonic tendency in the eastern Pacific are clearly detectable in both.

Cause and effect are difficult to infer from this analysis. It may not be possible to deduce whether the storm tracks are as they are because the stationary waves modulate them, or if the stationary waves are a response to the eddy forcing along the storm track. However, the answer should become clearer if one can determine how the wintertime circulation evolves, and this can be addressed by analyzing the monthly variability of the eddy forcing.

\section{Seasonal variability}

Eleven years of twice-daily ECMWF data were bandpass filtered over the entire period from January 1980 through December 1990 as described above. The resulting filtered data were then collected into individual months and monthly statistics were computed.

\section{a. Eddy kinetic energy and streamfunction tendencies}

The monthly mean 500-mb heights and vertically averaged eddy kinetic energy for the individual months October-February are shown in Fig. 6 and illustrate the evolution of storm track activity from fall to winter. The active region of the storm track at first intensifies and expands from October to November, reaching a maximum over both the Pacific and Atlantic Oceans. However, by December, in particular over the Pacific Ocean, eddy activity begins to diminish (actually its maximum values), the storm track axis deflecting poleward while the trough-ridge patterns begin to amplify. This decrease in eddy kinetic energy continues through January and February while the stationary trough and ridges exhibit further strengthening. This happens at a time when baroclinicity over the western Pacific is actually increasing, compared to fall, and could be a manifestation of the so-called midwinter suppression phenomenon $^{1}$ (Nakamura 1992).

\footnotetext{
${ }^{1}$ It should be noted from Fig. 6 that whereas the monthly maximum eddy energy decreases, the area covered is much larger in late winter than in fall, and the total eddy activity integrated over the Pacific Ocean in late winter is only slightly smaller than in late fall.
}

A detailed discussion of the reasons for this minimum will not be given here, but one interesting possibility is the fact that while a number of eddies from the Siberian storm track reach the warm waters of the Pacific Ocean in the fall, fewer actually reach the entrance of the storm track in the winter months, as evidenced in the decreased levels of eddy kinetic energy over eastern Asia as winter progresses (although Fig. 6 only depicts the vertically integrated eddy kinetic energy, the decrease of eddy activity over eastern Asia could be observed at all levels). This contrasts with the situation in the Atlantic, where eddy activity reaches a maximum in January, presumably because of a continuous and plentiful supply of eddies reaching the entrance of the storm track. Two possible explanations can be offered for the reduction of eddy activity seeding the entrance of the Pacific storm track. First, the surface air masses over Siberia tend to be very stable, offering a reduced baroclinicity to support waves moving through eastern Asia. Second, as the main jet moves south in winter, it has a tendency to become blocked by the Tibetan Plateau and the eddies are disrupted or otherwise prevented from propagating any further east. Either of these circumstances will have a strongly negative effect on Pacific storm track activity.

The monthly variability of the streamfunction tendency (deviations from the zonal mean) due to eddy forcing is shown in Fig. 7, together with the deviations from the zonal mean of the 500 -mb height contours shown in Fig. 6. A few general points should be underscored before discussing the characteristic forcing of the individual months. First, the forcing tends to increase from October through December, and decrease thereafter. Second, there is a high degree of correlation between the streamfunction tendency due to the highfrequency forcing and the actual height anomaly. This is perhaps the most important result supporting the premise of this paper. Third, there are distinct characteristics in the Atlantic and Pacific patterns. Over the Atlantic and Europe there is a persistent high anomaly and positive streamfunction tendency for most of the fall and winter. Over the Pacific Ocean, however, a more seasonal variability in the height anomaly and highfrequency forcing can be detected. The hypothesized role of the high-frequency eddies in forcing the quasistationary circulation definitely has a more predominant signature in the Atlantic storm track. However, the evolutionary aspect of the quasi-stationary pattern over the Pacific Ocean requires that a more rigorous argument be offered for its cause, which can carry over directly to the Atlantic storm track. A distinct intensification can be observed on the height anomalies and eddy forcing between November and December over the Pacific Ocean. The pattern in November displays primarily zonal, antisymmetric, elongated cyclonic and anticyclonic regions along each flank of the eddy kinetic energy maximum of Fig. 6. The height anomaly and streamfunction tendency are considerably intensified in December, with the streamfunction tendency displaying a pronounced 


\section{Vertically Averaged Eddy Kinetic Energy and 500mb Heights}
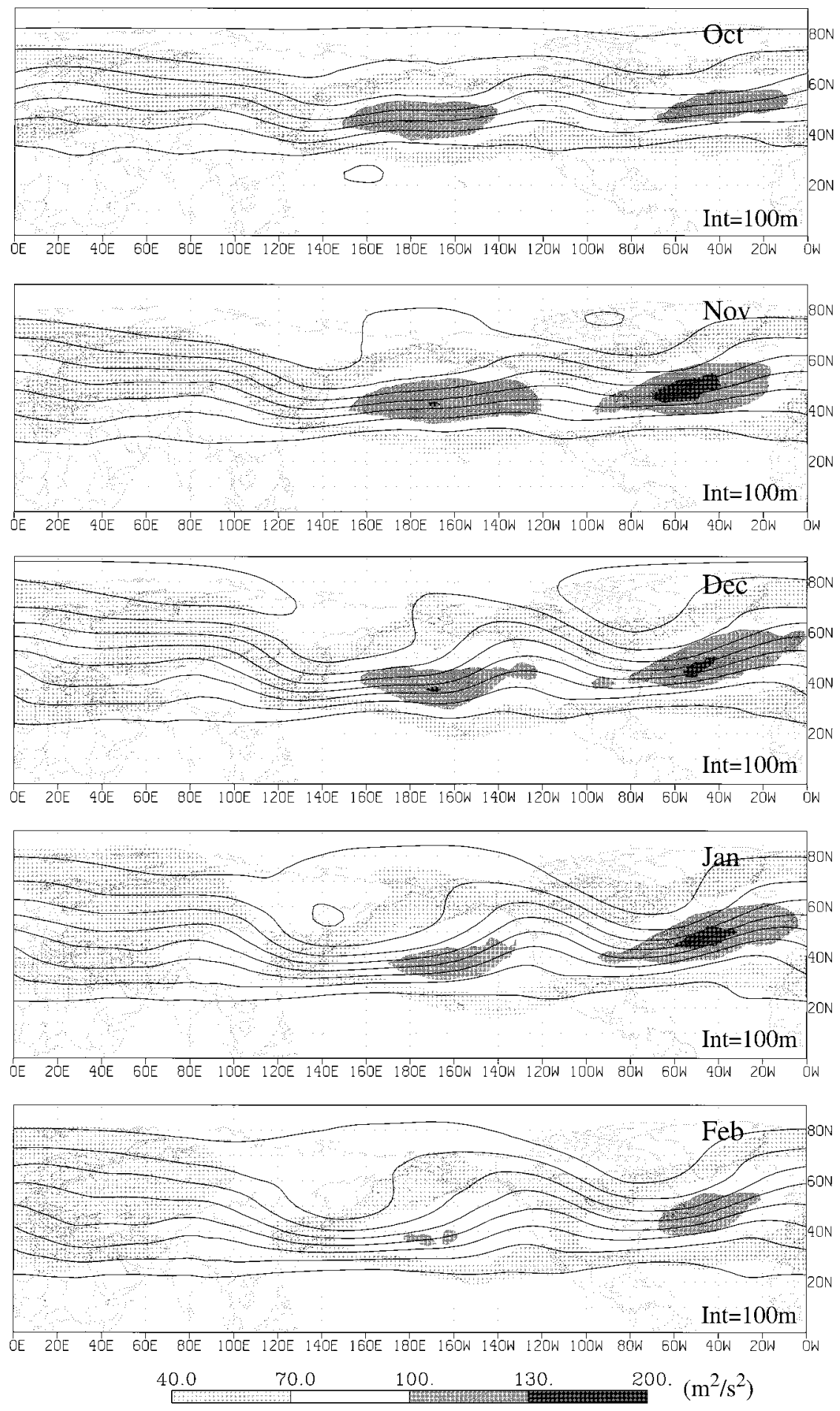

FIG. 6. The vertically and monthly averaged (1980-90) eddy kinetic energy and corresponding monthly average 500-mb geopotential height for October-February. Note the intensification of the eddy energy up to November, followed by the development of the eastern Pacific ridge and the subsequent decay of the eddy energy throughout the winter months in the Pacific storm track. 
$500 \mathrm{mb}$ Height and of Stream Function tendency (Deviations from zonal mean) (Monthly averages during 1980-1990)
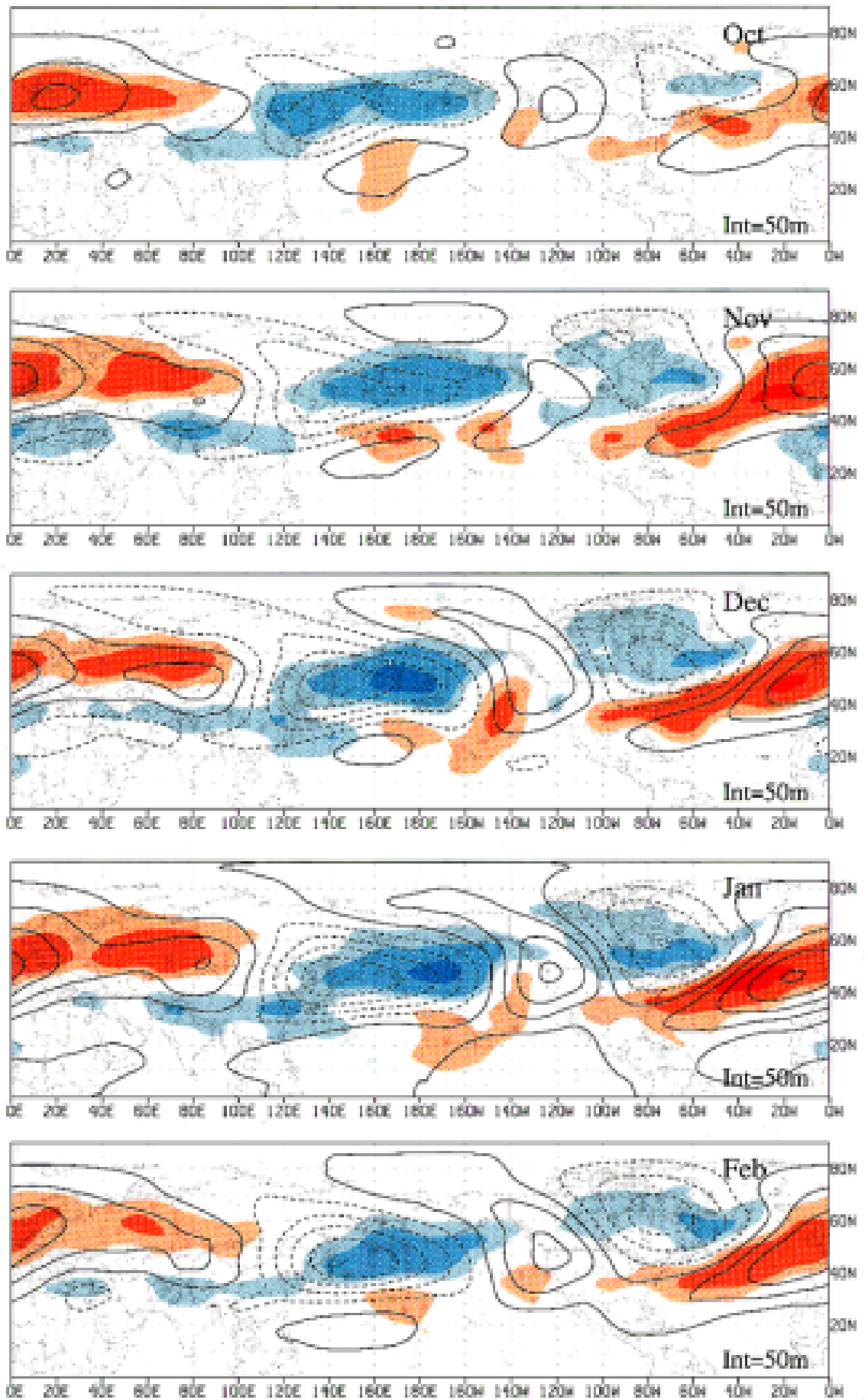

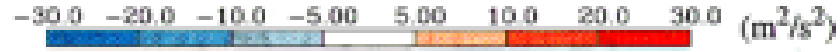

FIG. 7. Anomalies of the streamfunction tendency due to eddy forcing for the monthly average over the 11yr period, October-February. The 500-mb height deviations are shown for references. Deviations here are the deviations of the zonal mean for each month. Notice the strong correlation between streamfunction tendencies and height anomalies, in particular for the Atlantic storm track, and the enhanced quadrupole signature in December over the Pacific region. 
positive amplitude in the eastern Pacific, and the area of cyclonic tendencies shifts to the west. These anomalies have a similar phase relation to the trough and ridge over the storm tracks, as was shown in Fig. 1c, for the winter season. In fact, the similarity of the December case and that of the full winter shown in Fig. $1 \mathrm{c}$ gives statistical significance to this subset. At this point, it will be instructive to analyze the individual contributions to the tendency by $\overline{u^{\prime} v^{\prime}}$ and $\left(\overline{v^{\prime 2}}-\overline{u^{\prime 2}}\right)$, as was done for the mean winter circulation (Fig. 5).

\section{b. Individual contributions}

The total streamfunction tendency and its component contributions for the month of November are shown in Figs. 8a,b, and for December in Figs. 8c, d. In the case of the Pacific storm track, the main contribution in November comes from the poleward flux of zonal momentum, $\overline{u^{\prime} v^{\prime}}$ (Fig. 8a), which has a quite elongated dipole structure about the mean jet. The contribution from $\left(\overline{v^{\prime 2}}-\overline{u^{\prime 2}}\right)$ (Fig. 8b) displays the characteristic quadrupole pattern, but its magnitude is much smaller.

A distinct change in the pattern occurs in December. The positive and negative amplitude of the quadrupole contributions of $\left(\overline{v^{\prime 2}}-\overline{u^{\prime 2}}\right)$ shown in Fig. 8d are now considerably larger and contribute almost as much to the total tendency as $\overline{u^{\prime} v^{\prime}}$ (Fig. 8c). Note, also that the positive area in the pattern of $\overline{u^{\prime} v^{\prime}}$ is more meridionally extended at its eastern end, probably suggesting the presence of the ridge. The pattern of the streamfunction tendency due to $\left.\overline{\left(v^{\prime 2}\right.}-\overline{u^{\prime 2}}\right)$ is very much in line with the increase in the amplitude of the trough-ridge system observed in the mean monthly heights. These results suggest that the high-frequency eddy forcing may well be responsible for the slow changes in the atmospheric circulation over the Pacific region. Because the winter eddy forcing has already been shown to be larger than the vertically integrated frictional effects (see Fig. 5), it is logical to conclude that the rest of the eddy forcing is showing up in the mean circulation tendency. The question that remains unanswered then, is why $\overline{\left(v^{\prime 2}\right.}-$ $\overline{u^{\prime 2}}$ ) (and to a lesser degree $\overline{u^{\prime} v^{\prime}}$ ) behave so differently during the evolution of the winter circulation.

\section{c. Eddy correlations}

Given that the streamfunction tendency differs so markedly from November to December, it is instructive to examine the actual eddy correlations themselves (i.e., $\overline{u^{\prime} v^{\prime}}$ and $\left(\overline{v^{\prime 2}}-\overline{u^{\prime 2}}\right)$. Figures 9a,b display these two quantities for November and Figs. 9c,d for December, along with the eddy kinetic energy for reference. Note that both terms display a pattern similar to that shown in the schematics of Fig. 3. In particular, $\left(\overline{v^{\prime 2}}-\overline{u^{\prime 2}}\right)$ is very elongated, with a maximum in the eastern Pacific, which may be due to the irreversible decay of eddies as they encounter the western North American orography (Fig. 9b). There, wave breaking produces an en- strophy cascade, and the eddies become elongated in the meridional direction, thus increasing $\overline{v^{\prime 2}}$ far more than $\overline{u^{\prime 2}}$. Both $\overline{u^{\prime} v^{\prime}}$ (Fig. 9c) and $\overline{\left(v^{\prime 2}\right.}-\overline{u^{\prime 2}}$ ) (Fig. 9d) for the month of December exhibit a difference in the patterns compared to November (Figs. 9a,b), which is consistent with the difference in vorticity forcing. In December, the primary activity seems more confined to the central and western Pacific, decaying quickly east of $150^{\circ} \mathrm{W}$. This suggests that, as the winter progresses, eddies begin to decay sooner, closer to the baroclinic source, at around $160^{\circ} \mathrm{W}$ compared to approximately $120^{\circ} \mathrm{W}$ in November. If the maximum in $\left(\overline{v^{\prime 2}}-\overline{u^{\prime 2}}\right)$ is any indication, the decay is probably by irreversible wave breaking.

\section{d. Sources and sinks for the storm track}

So far, only the relationship between the eddy forcing and the stationary circulation has been discussed. To fully interpret the difference in storm track behavior between November and December, an analysis of the sources and sinks of eddy energy due to the mean circulation is needed.

\section{1) The BARoclinic SOURCE}

It is well known that baroclinic development operates primarily in the lower levels of the atmosphere. The 700-mb Eady growth rate, estimated from the monthly mean state as $\sigma=0.31(f / N)(d / d z) \bar{U}$, can be a useful measure of the low-level baroclinicity (Hoskins and Valdes 1990). Here, $f$ is the coriolis parameter, $d U / d z$ is the vertical shear of the zonal component of the mean wind, and $N$ is the local Brunt-Väisälä frequency. The Eady growth rate for the mean November conditions is shown in Fig. 10a, and the November-December difference is shown in Fig. 10b. Another useful measure of baroclinic eddy activity is the low-level meridional heat fluxes due to high-frequency transients, $\overline{v^{\prime} T^{\prime}}$. The 850 -mb heat fluxes for November are shown in Fig. $10 \mathrm{c}$, with the November-December difference shown in Fig. 10d. One additional measure of eddy activity at lower levels in the atmosphere is the variance of the meridional velocity, $\overline{v^{\prime 2}}$, which is shown in Fig. 10e at $850 \mathrm{mb}$, again with the November-December difference shown in Fig. 10f. In all of these figures, the vertically averaged eddy kinetic energy for the months of November (left) and December (right) are shown for reference.

A strong correlation can be seen between $\sigma$ and $\overline{v^{\prime} T^{\prime}}$, consistent with the findings of Hoskins and Valdes (1990). They cautioned, however, that horizontal shear and moisture could modify the effectiveness of the baroclinicity. James (1987) also pointed out that the horizontal shear could reduce the effect of the baroclinicity on the eddies. It should also be noted that any increase in the strength of the low-level mean flow could be unfavorable for baroclinic development because of the 
Individual Contributions to the Vertically Averaged Stream Function Tendency November 1980-1990
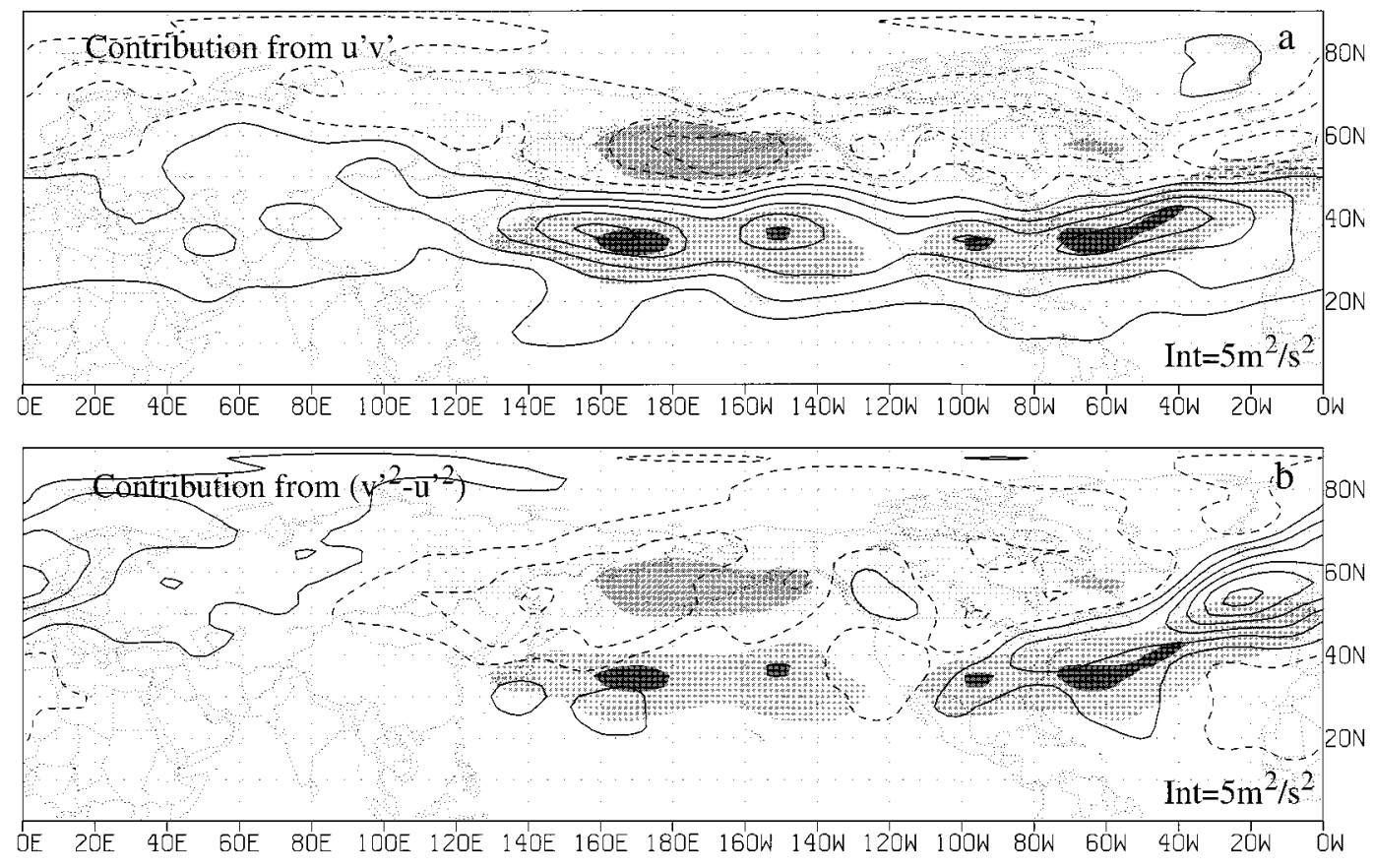

December 1980-1990
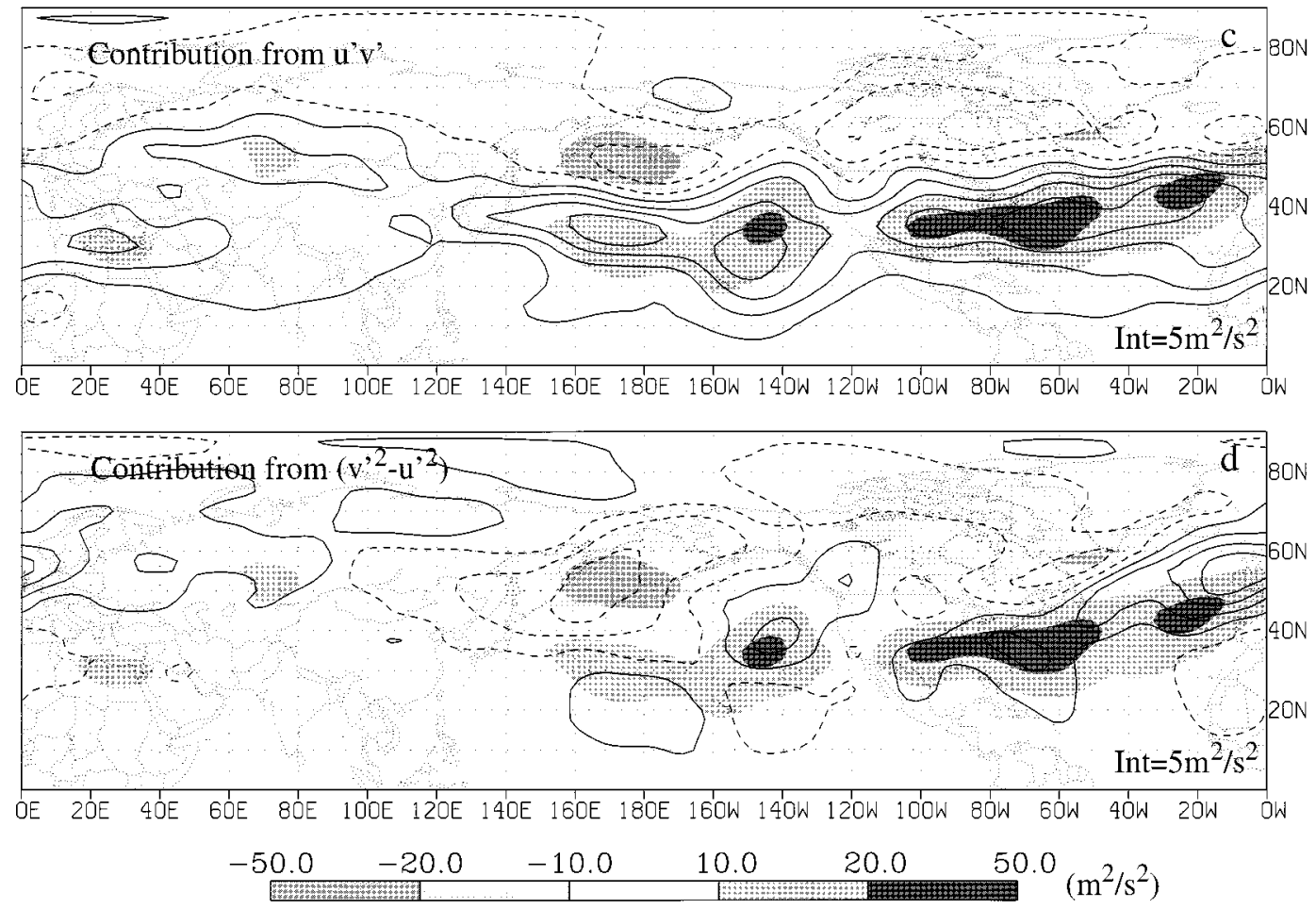

FIG. 8. Same as Fig. 4 but for the November (top two panels) and December (bottom two panels) means. 


\section{Elements of the Horizontal Velocity Correlation Tensor (anisotropic part) November 1980-1990}

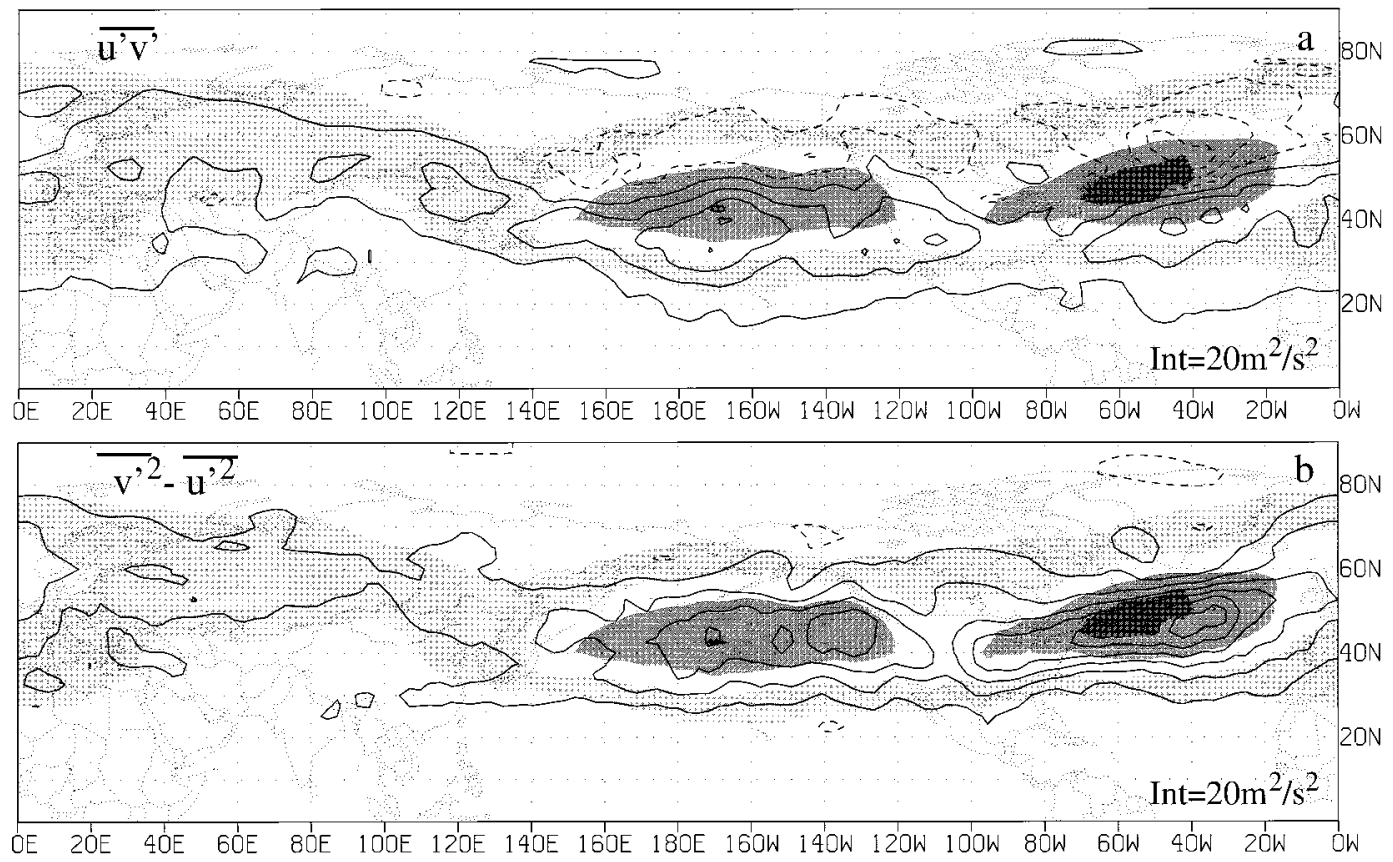

December 1980-1990
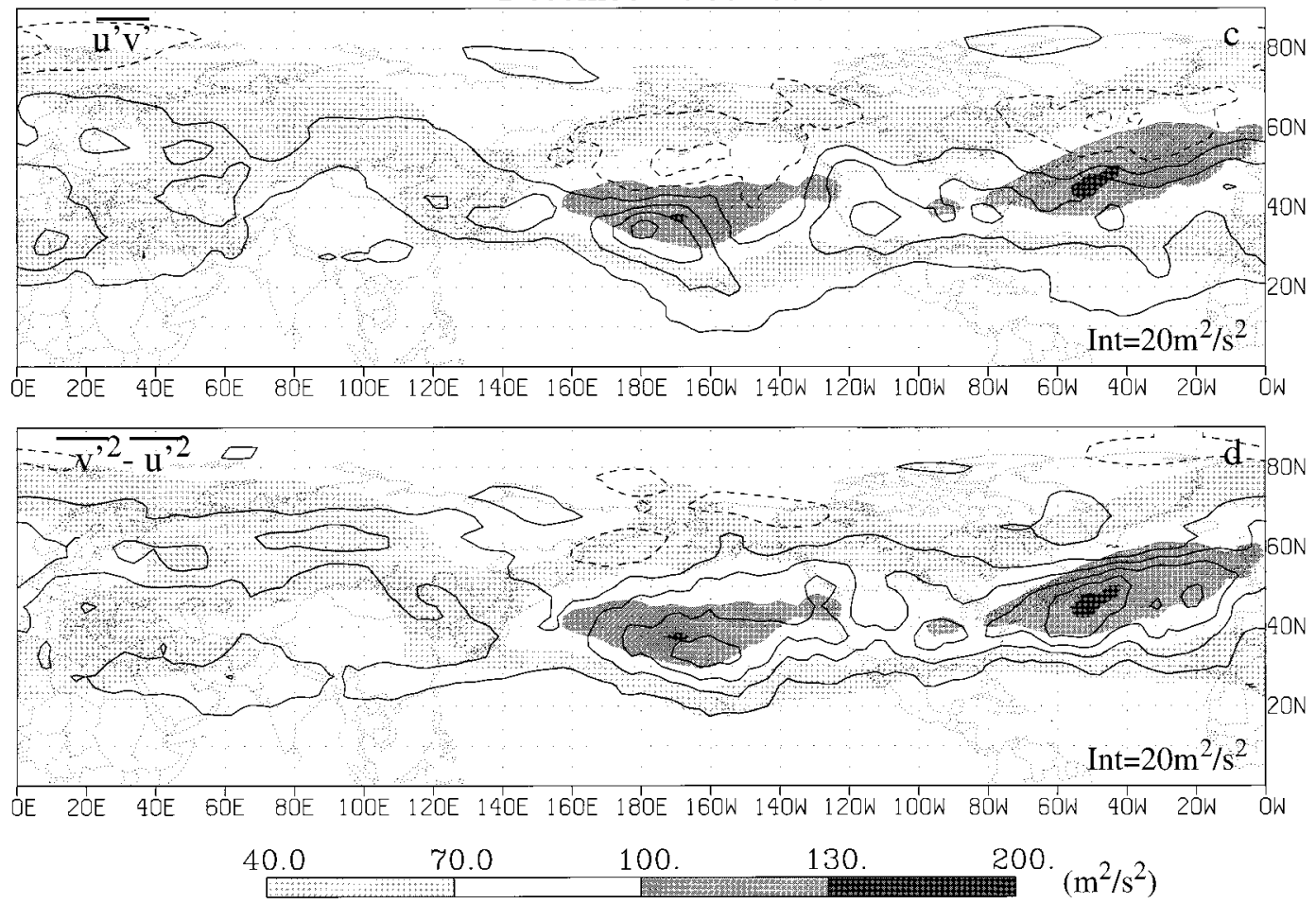

FIG. 9. Vertically averaged eddy correlations $\overline{u^{\prime} v^{\prime}}$ and $\overline{v^{\prime 2}}-\overline{u^{\prime 2}}$ for the months of November and December. The eddy kinetic energy fields from Fig. 6 are shown for reference. Note the maxima in the correlations around $160^{\circ} \mathrm{W}$ for the month of December. 
November

Difference (November-December)

Baroclinicity of the mean flow $(700 \mathrm{mb})$
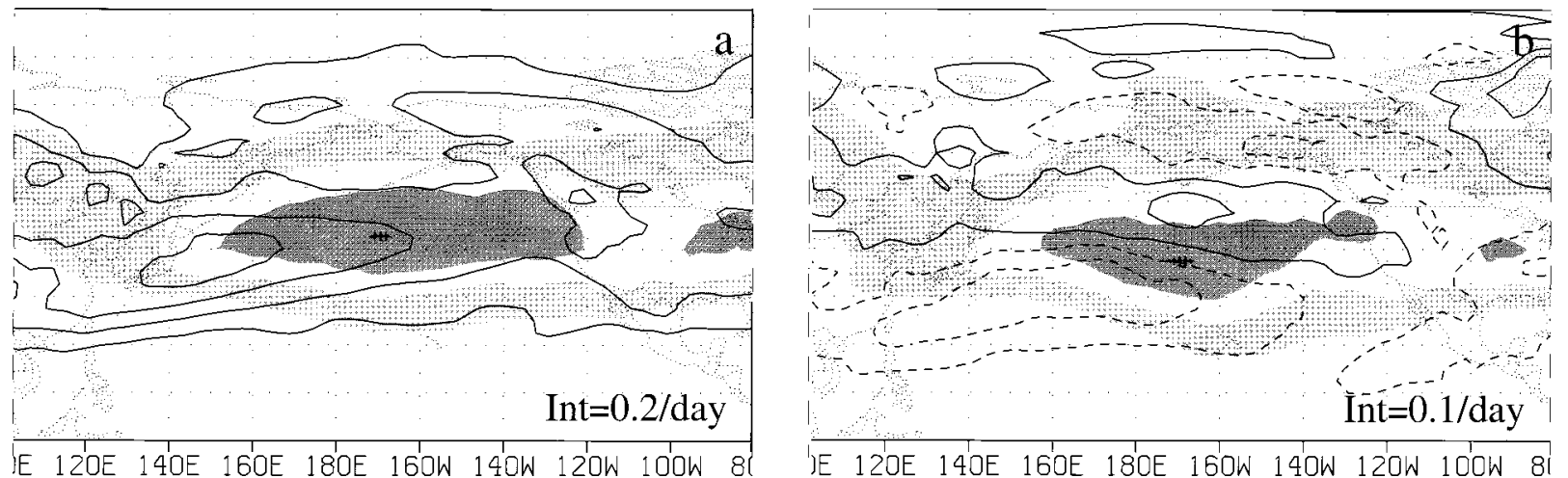

Meridional heat flux t'v'(850mb)
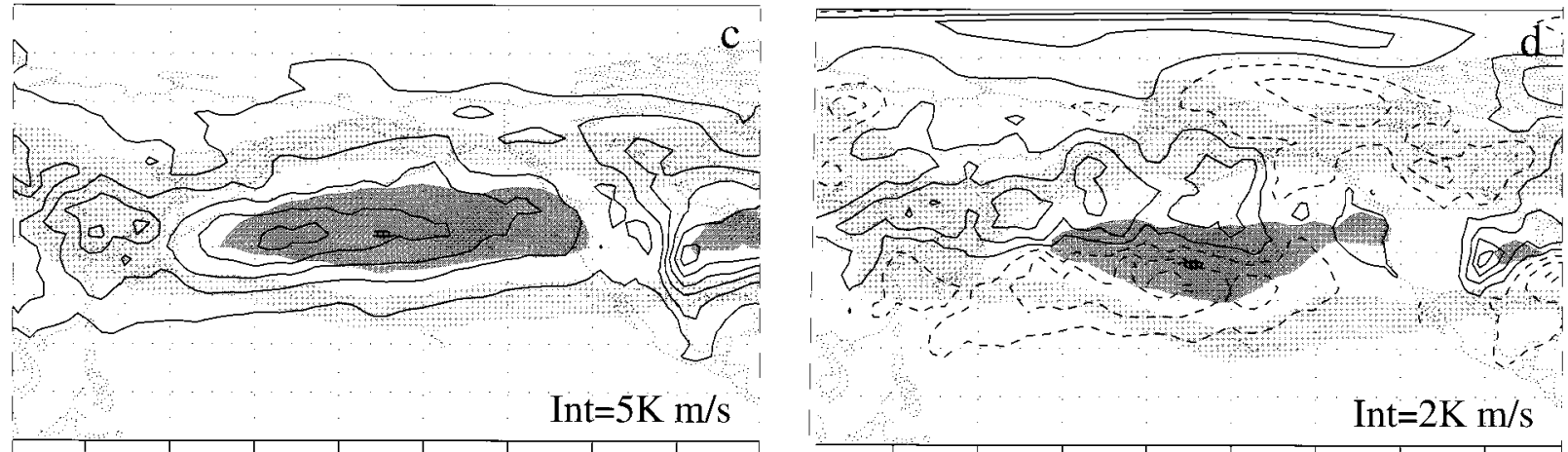

IE 12OE $140 \mathrm{E}$ 160E 180E 16OW 14OW LOW 10OW \&

IJE 12OE 14OE 16OE 18OE 16OW 14OW 12OW 10OW 8

\section{Variance of meridional velocity $\overline{v^{, 2}}(850 \mathrm{mb})$}
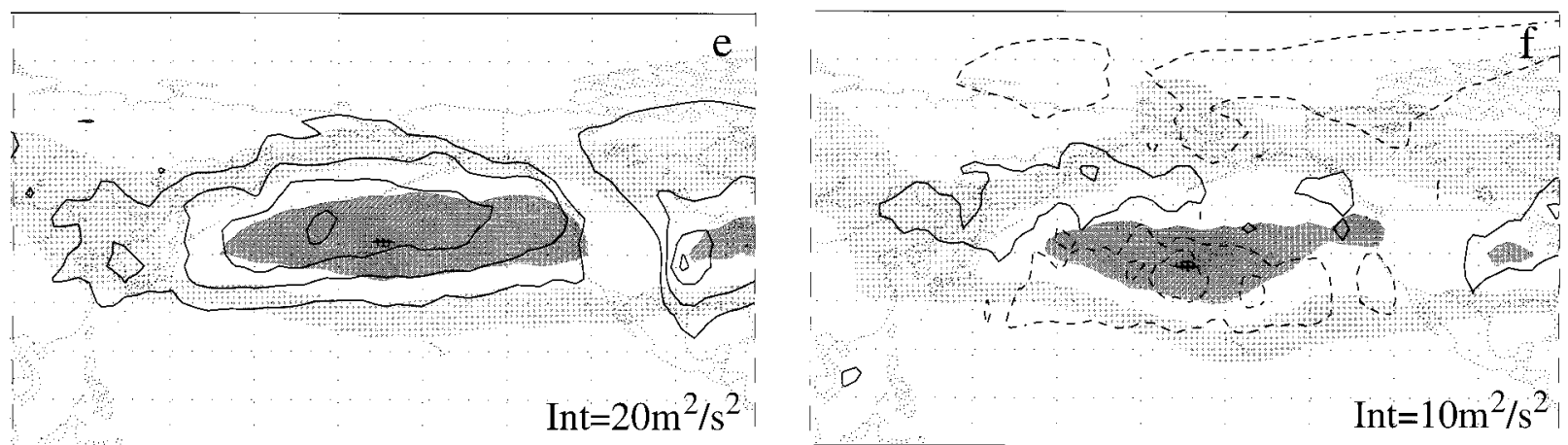

JE 120E 140E 160E 180E 160W 140W 120W lón 8I

IJE 120E 140E 160E 180E 16OW 140W 12OW 100W 81

FIG. 10. (a) and (b) Low-level mean flow baroclinicity. (c) and (d) Eddy heat fluxes at $850 \mathrm{mb}$. (e) and (f) Variance of the meridional velocity at $850 \mathrm{mb}$. The left panels are for November, and the right panels are the differences (November minus December). Note the increase in the baroclinicity of the mean flow in December near the entrance of the storm track. 
reduced residence time of the eddies in the baroclinic zone. These issues are discussed in greater detail later in this section.

The results of Emanuel et al. (1987, hereafter EFT) suggest that the enhancement of baroclinicity by moisture in the atmosphere could be substantial. To help explain the differences between November and December, we approximate, based on EFT numerical estimates, a moist Eady growth rate as follows:

$$
\sigma_{M}=\sigma_{D}\left[1+(1-r)^{n}\right],
$$

where $\sigma_{D}$ is the Eady growth rate for the dry atmosphere and $r$ is defined as

$$
r=\frac{\Gamma_{M}}{\Gamma_{D}}\left(\frac{L_{v}}{C_{p}} \frac{d q_{s}}{d z}\right)\left(\frac{d T}{d z}+\Gamma_{D}\right)^{-1},
$$

where $\Gamma_{m}$ and $\Gamma_{D}$ are moist- and dry-adiabatic lapse rates, respectively; $L_{v}$ is the latent heat of condensation; $C_{p}$ is the heat capacity at constant pressure; and $q_{s}$ is the saturation specific humidity. The quantity $r$ is the ratio between the moist and dry quasigeostrophic potential vorticiy, as defined by EFT, who showed that the moist unstable Eady normal modes could have a growth rate twice that of the dry atmosphere for $r=0$. The expression (3.1) is a good empirical approximation of EFT's results for values of $n$ between 3 and 5. The numerical values of $\sigma_{m}$ are significantly different from $\sigma_{D}$ only when $r$ is close to zero. Since the choice of $n$ will not affect the estimate much, we chose $n=3$ in (3.1). We find maximum differences in growth rate within $10 \%$ to $15 \%$ of the dry values, which is not significant. The geographical areas of high baroclinicity were unchanged. The similarity between the dry and moist Eady growth rates is most likely due to the fact that the atmosphere in these months is quite cold. The moist meridional flux at $850 \mathrm{mb}$ was also computed (though not shown here) and its characteristics were found to be very similar to those of the heat and moisture fluxes. This is consistent with our previous conclusion that the winter atmosphere is so cold that no considerable latent heating is produced during moist development. Given these results, the remaining discussion will be limited to the dry atmosphere.

Referring again to Fig. 10, note the consistency between the changes in the distribution of baroclinicity and that of the meridional fluxes. In general, December displays a more equatorward and slightly more intense low-level storm track than November (negative regions in Figs. 10d,f). What is probably more interesting is the fact that the negative changes (dashed contours) in the eddy fluxes occur downstream of the changes in the baroclinicity, with increases in the latter (negative region, Fig. 10b) occurring primarily in the western Pacific. This is consistent with earlier suggestions that eddies entering the baroclinic zone in November are already reasonably vigorous, while those entering the baroclinic zone in December are much weaker and do not become as vigorous until they are further along the storm track.

One thing common to both November and December is the consistency between the distribution of low-level eddy activity and the baroclinic zone, as defined from the monthly mean flow; that is, the amplitude of the meridional velocity variance is found slightly downstream of the baroclinicity maximum. As discussed by Hoskins et al. (1983), and Chang and Orlanski (1993), the eddies grow initially by baroclinic processes at the entrance of the storm track. As they mature, they flux energy upward and downstream, producing new eddies. Because these new eddies already have a source of energy in the form of upstream energy fluxes, they do not require as much baroclinicity. As a consequence, the vertically integrated eddy energy will reach a maximum well downstream of the actual baroclinic energy source. If, during the winter months, there is a decrease in the "seeding" of eddies from the Asian storm track, the overall level of eddy energy may decrease. Although, the termination of the storm track cannot be so simply attributed to this lack of seeding, we shall see that the confined area of intense baroclinicity in the western $\mathrm{Pa}-$ cific is of great importance to the downstream termination.

\section{2) THE BAROTROPIC SINK}

As shown above, the development of the eastern Pacific ridge by the action of the HF transient eddies enhances the diffluence of the westerlies. It has been suggested by Witaker and Dole (1995), Mak and Cai (1989) and others, that "stretching" deformation is an effective sink of eddy activity. Mak and Cai (1989), in discussing the stability of a nonzonal barotropic jet, have shown that the interaction between the time-mean flow and the transient eddies in a Cartesian system could be expressed as an "interaction" term as follows:

$$
I=\mathbf{E} \cdot \mathbf{D} \begin{cases}>0 & \text { eddies gain energy from the mean flow } \\ <0 & \text { eddies lose energy to the mean flow, }\end{cases}
$$

where $\mathbf{E}$ is the $\mathbf{E}$-vector $\left(\frac{1}{2}\left(\overline{v^{2}}-\overline{u^{2}}\right),-\overline{u v}\right.$ ) (Hoskins et al. 1983; Lau 1988; Mak and Cai 1989) and D is the deformation vector with components in the Cartesian coordinates given by

$$
\mathbf{D}=\left(\frac{\partial U}{\partial x}-\frac{\partial V}{\partial y}, \frac{\partial V}{\partial x}+\frac{\partial U}{\partial y}\right)
$$

The $x$ component of the deformation vector represents stretching deformation and the $y$ component the shear deformation. If the interaction term is positive (negative) the eddies gain (lose) energy. The components of the $E$-vector already have been discussed (Fig. 9) for both November and December, so the remaining discussions will concentrate on the components of the $D$ vector. 
Time Mean Westerly Wind and Deformation (vertically averaged)

November

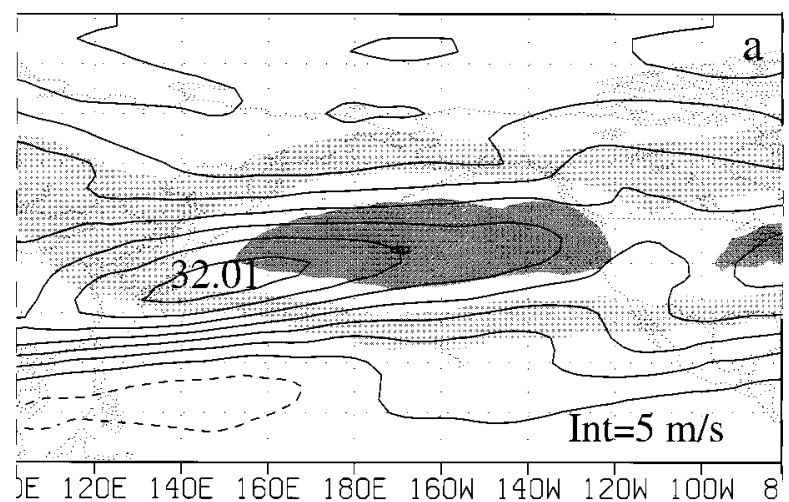

Shear Deformation

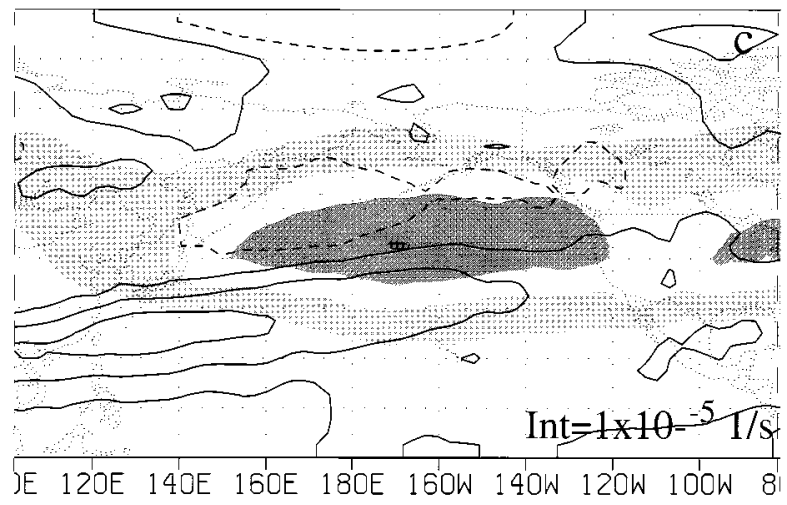

Stretching Deformation

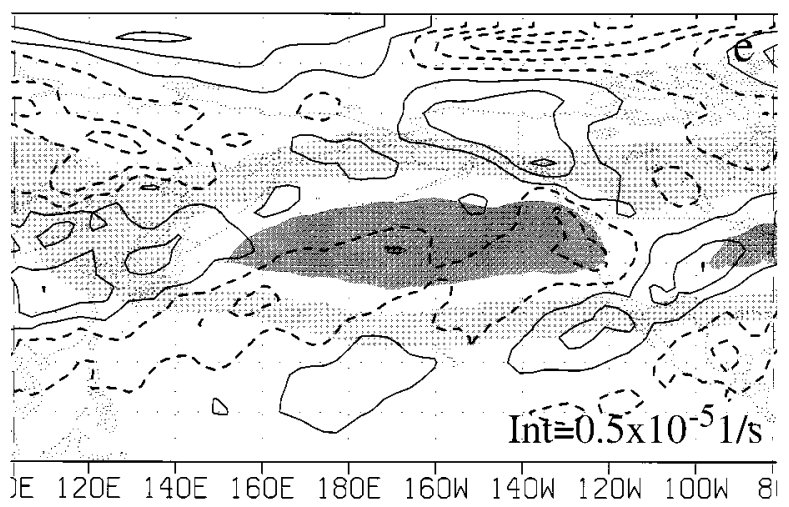

December

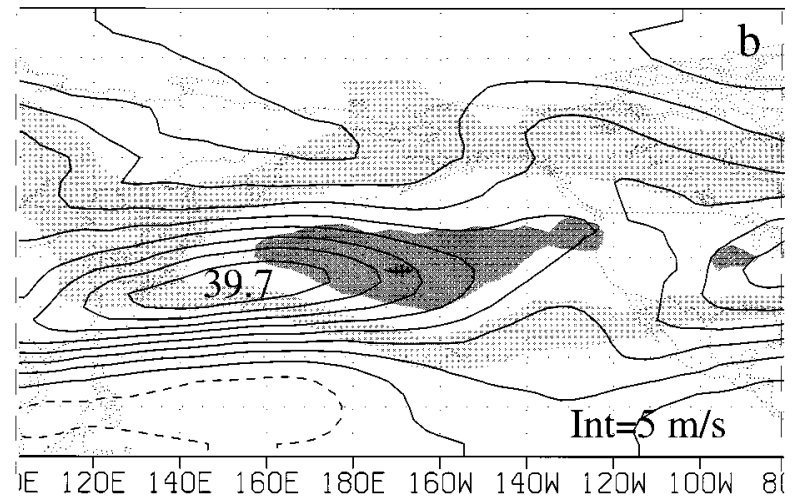

$\frac{1}{\operatorname{acos} \phi} \frac{\mathrm{d} \overline{\mathrm{V}}}{\mathrm{d} \lambda}+\frac{\mathrm{d} \overline{\mathrm{U}}}{\mathrm{ad} \phi}$

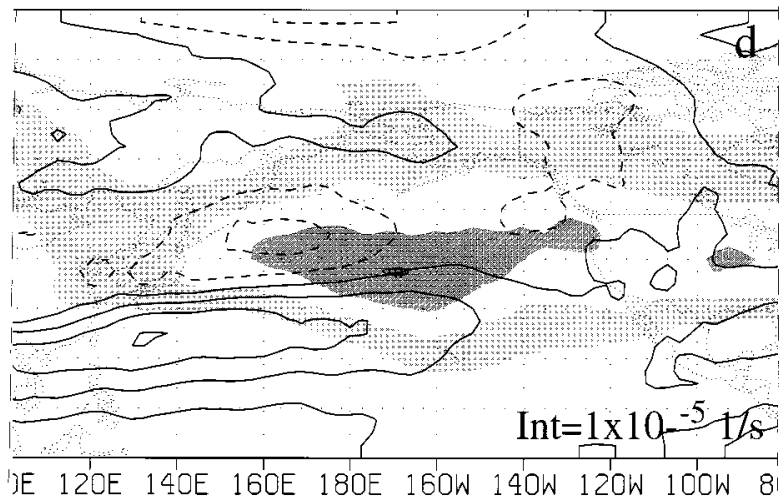

$\frac{1}{\operatorname{acos} \phi} \frac{\mathrm{d} \overline{\mathrm{U}}}{\mathrm{d} \lambda}-\frac{\mathrm{d} \overline{\mathrm{V}}}{\mathrm{ad} \phi}$

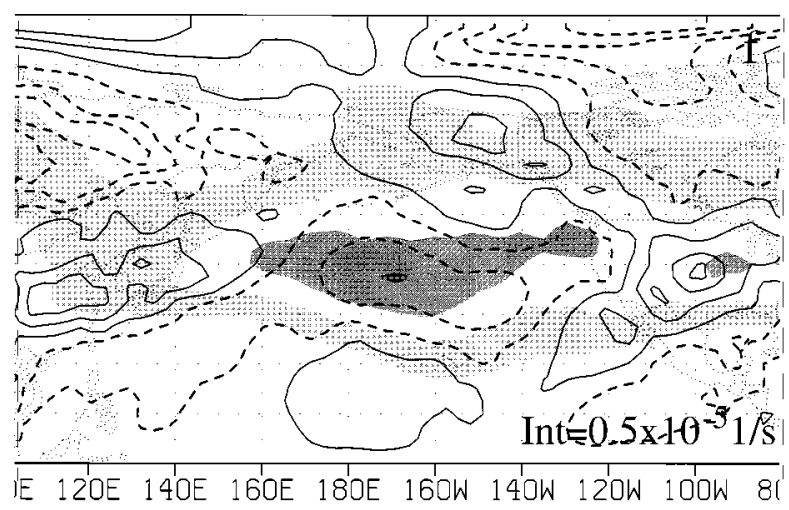

FIG. 11. Vertically averaged zonal wind and the two components of the deformation vector for November (left panels) and December (right panels).

Figure 11 depicts the vertically averaged zonal velocity, together with the two components of the $D$ vector for November and December. (Note that the fields shown are the complete fields rather than differences as in the previous figure.) The vertically averaged eddy kinetic energy for November and December are shown for reference. The strongest barotropic winds occur over the entrance of the storm track, with December's wind 
maximum $\left(39.7 \mathrm{~m} \mathrm{~s}^{-1}\right)$ stronger than November $(32.01$ $\mathrm{m} \mathrm{s}^{-1}$ ). This increased intensity is a negative factor for baroclinic growth of eddies because it reduces the residence time for eddies traversing the area of strongest baroclinicity. The shear deformation for both months mainly reflects the shear of the westerly flow, the stronger flow in December contributes to larger cyclonic (negative values) and anticyclonic shear (positive values), which is also less conducive to baroclinic development. An inspection of Figs. 9a,c indicates that the $E$-vector points northward on the poleward side of the storm track axis and southward on the equatoward side for both months. The meridional component of the deformation vector points in the opposite direction on each side of the storm track so the interaction (3.3) constitutes a sink of eddy energy, which is stronger in December than November. Finally, the stronger (negative) stretching deformation in the middle of the storm track during December (Fig. 11f), combined with the primarily positive zonal component of the $E$-vector (see Figs. 9b,d) could constitute a sink of eddy energy, which is considerably larger in December.

To the extent that the eddy forcing as shown in Fig. $8 \mathrm{~d}$ tends to enhance the trough-ridge system for the month of December, it also intensifies the barotropic shear deformation at the base of the trough and the stretching deformation (diffluence) at the ridge. In this way, the eddy activity actually appears to produce an environment hostile to the eddies themselves. The combined effect seen in the streamfunction tendency forced by the eddies (Fig. 7) acts in such a way as to enhance the trough-ridge character of the storm track, intensifying the barotropic flow and shear deformation in the trough and the difluence and stretching deformation in the ridge. These are precisely the conditions associated with a loss of eddy energy. The extended baroclinicity source, then, is perhaps the only reason that the storm track is maintained. But as we have seen, it is not enough to have intense baroclinicity at the entrance of the storm track. In fact, such a condition could be counterproductive because the faster-developing low-level eddies will develop faster, producing stronger heat fluxes, which will dissipate the baroclinicity downstream through vigorous heat fluxes. Without the extended source of baroclinicity, the waves will break, producing, a poleward deflection, and a strong diffluence that will inhibit baroclinic development of the eddies and terminate the storm track. One way to test the role of the downstream baroclinicity would be to examine the conditions surrounding years in which the storm track is unusually extended, such as that found during the warm phase of the ENSO cycle (Lau 1985; Held et al. 1989).

\section{Interannual variability}

\section{a. The mean circulation}

Interannual variability of the mean circulation, in particular that associated with the ENSO cycle, includes differences in the shape and intensity of the Pacific storm track (Lau 1985; Held et al. 1989). It might be expected, then, that the monthly variations in the eddy forcing patterns from fall to winter might have an analog in the phases of the ENSO cycle. The 11 years of data were sorted according to whether the sea surface temperature (SST) anomaly in the tropical eastern Pacific (the El Niño 3 region) was greater than $0.75^{\circ} \mathrm{C}$ (warm events) or less than $-0.65^{\circ} \mathrm{C}$ (cold events). For the period of the dataset being used, only two major warm events $(1982,1986)$ and two cold events $(1984,1988)$ occurred, so the limited nature of this dataset must be kept in mind when drawing any conclusions.

The mean wintertime (December-February 19801990) 500-mb heights are shown in Fig. 12, together with the height anomalies associated with the warm and cold events. Although the patterns displayed have similarities with the well-known Pacific-North America (PNA) pattern (Horel and Wallace 1981), the differences are notable. In particular, the position of the high anomaly over North America shown for the warm events in Fig. 12a is considerably east of that reported by Horel and Wallace (1981). Probably two major factors are responsible for such a distinction: (a) two large atypical events were present in this dataset-El Niño of 1982 and La Niña of 1988, and (b) the criterion for selecting the warm and cold events was somehow weaker than used by other researchers (e.g., $\mathrm{T}>1.0^{\circ} \mathrm{C}$ for warm events and $\mathrm{T}<-1.0^{\circ} \mathrm{C}$ for cold events). ${ }^{2}$ However, this selection was sufficiently adequate to separate the distinct characteristics of the Pacific storm track in the socalled warm and cold events. The selected warm events capture reasonably well the tendency to have an elongated westerly jet over the Pacific Ocean and a weaker ridge in the eastern Pacific, whereas a pronounced eastern Pacific ridge was found for the cold events.

\section{b. Eddy characteristics}

The eddy kinetic energy and the corresponding 500$\mathrm{mb}$ heights associated with the warm and cold ENSO phases are shown in Fig. 13. In the Pacific, the eddy activity during the warm phase is slightly stronger and lacks the southwest-northeast tilt (poleward deflection) present in the cold phase. In contrast, the eddy activity in the Atlantic is stronger during cold events. The eddy kinetic energy distributions for the warm and cold phases display a striking similarity with those of November and December, respectively (as shown in Fig. 6). The 500-mb heights are quite similar in the overall patterns during warm and cold events. However, it is clear that the position of the ridge in the eastern Pacific and western North America is displaced eastward for

\footnotetext{
${ }^{2}$ Using the more traditional values for selecting warm and cold events was found a slightly better comparison with the PNA pattern, but this reduces considerably the number of days in each class.
} 


\section{Warm Events}

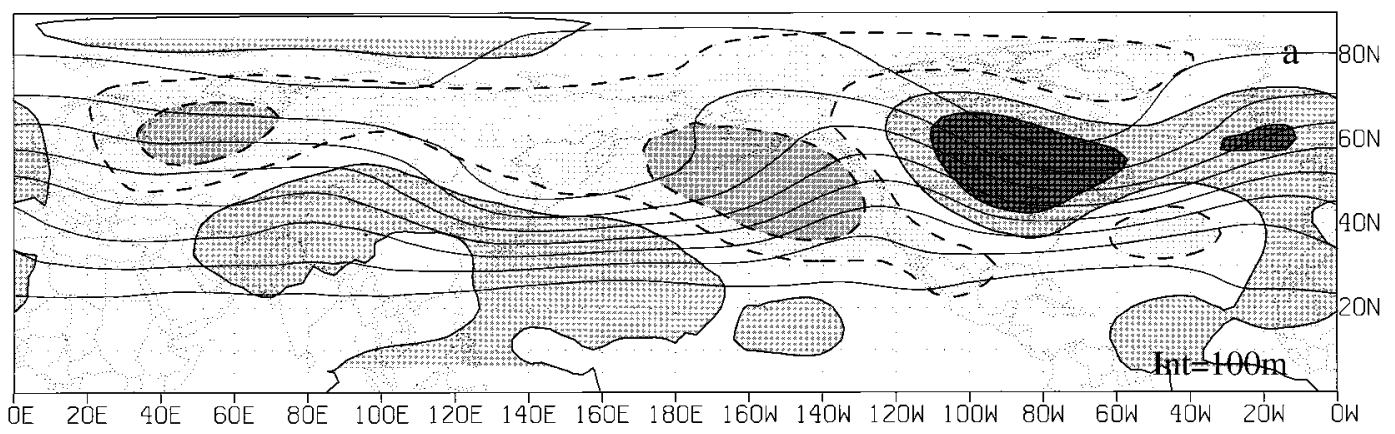

\section{Cold Events}

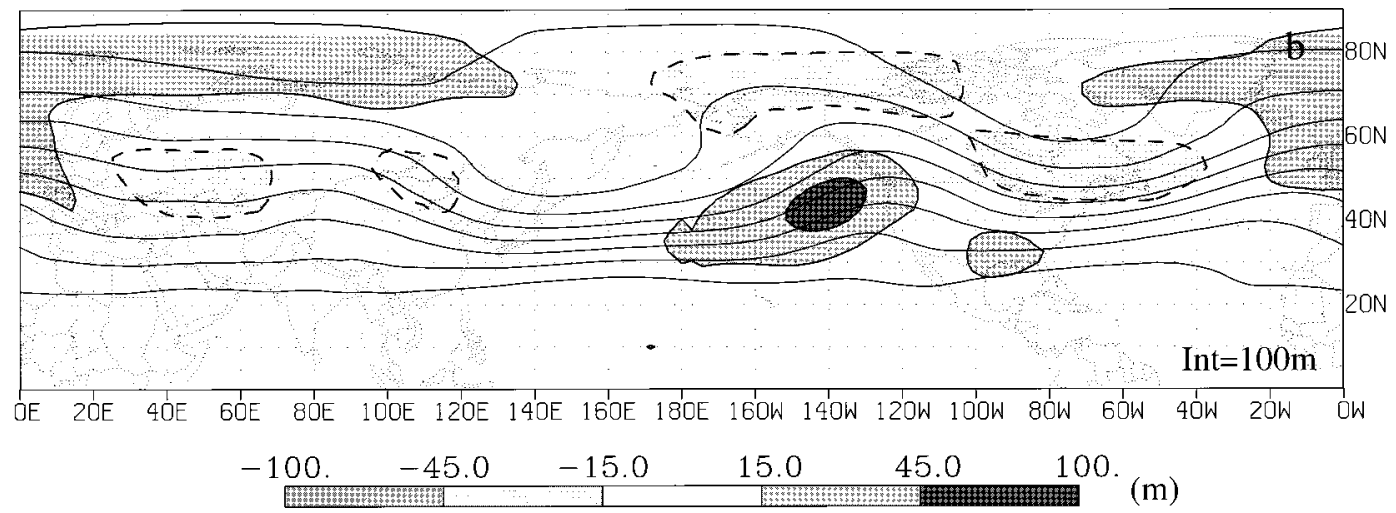

FIG. 12. The 500-mb geopotential height anomaly for a composite of the ENSO (a) warm events and (b) cold events. The anomaly is calculated with respect to a total 11-yr winter mean (December-February), and contours of the 500-mb geopotential height for that total mean are shown for reference.

the warm phase. The differences between the 500-mb heights are more clearly detected when the deviations from the zonal average are displayed. Figure 14 shows the deviation from the zonal mean for the $500-\mathrm{mb}$ heights (contours) together with the deviation of the streamfunction tendencies (bands). The positive height anomaly covers most of western North America in the warm events and is displaced westward by about $20^{\circ}$ long in the cold phase.

Although the height anomaly in Fig. 12 could be related to the PNA pattern, this pattern could also be attributed to a longitudinal displacement of the troughridge system over the Pacific Ocean. The most revealing differences are seen by inspecting the anomalies of the streamfunction tendencies for warm and cold events in Fig. 14. The elongated shape of the positive and negative anomalies in the warm events (Fig. 14a) covers most of the Pacific Ocean and is in agreement with the elongated shape of the eddy kinetic energy displayed in Fig. 13a. In the cold events, however (Fig. 14b), a markedly different pattern is observed. The streamfunction anomalies are partially in phase with the heights anomalies. The positive streamfunction tendency has a large meridional extent, slightly upstream of the positive height anomaly over the eastern Pacific Ocean. The overall pattern of the deviation streamfunction tendency of the cold events is quite similar and more intense than the that for the mean winter shown in Fig. 1c. As a matter of fact the tendencies for the two phases (shown in Fig. 14) are very similar to the tendencies in November and December (Fig. 7). This similarity is not surprising since as previously mentioned the eddy kinetic energy is quite similar as well. These results justify the need to analyze the interannual variability of the storm tracks to find out why some winter seasons do not exhibit the characteristic decline of eddy activity observed in normal years.

The eddy vorticity forcing terms contributing to the streamfunction tendencies for the two ENSO phases are shown in Fig. 15. As one would imagine, the fields display pronounced high-wavenumber variability. The elongated forcing for the warm events and the strong poleward deflection in the cold events is clearly evident. Given the direct relationship between this and the curl of the surface wind stresses, it should come as no surprise that the curl of the surface drag (not shown here) displays a similar pattern for the warm and cold events. 


\section{Vertically Averaged Eddy Kinetic Energy and 500mb Heights DJF 1980-1990}

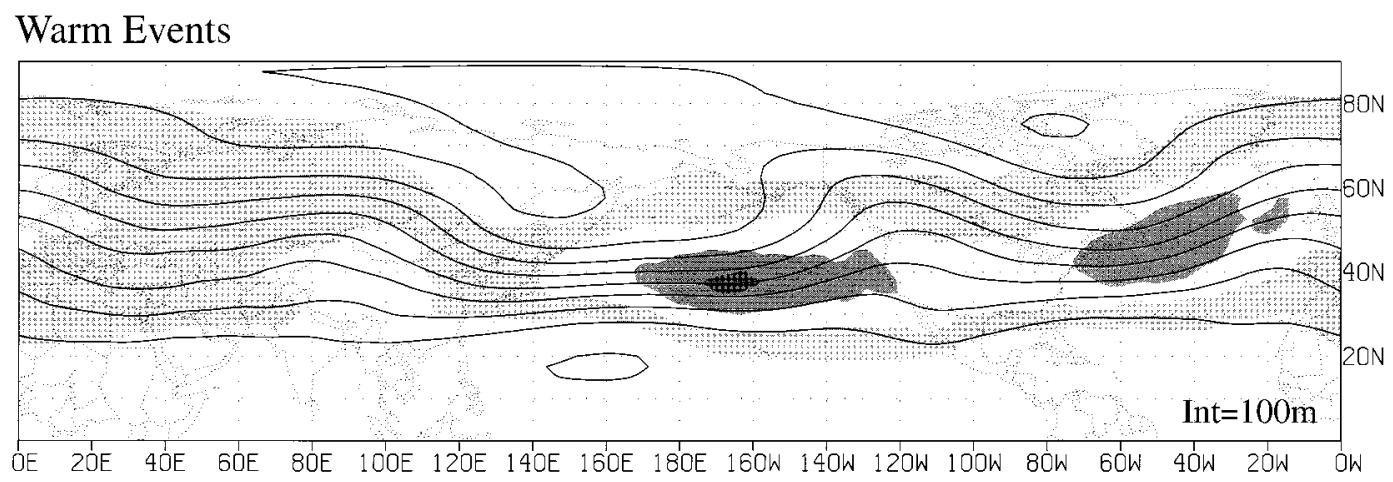

\section{Cold Events}

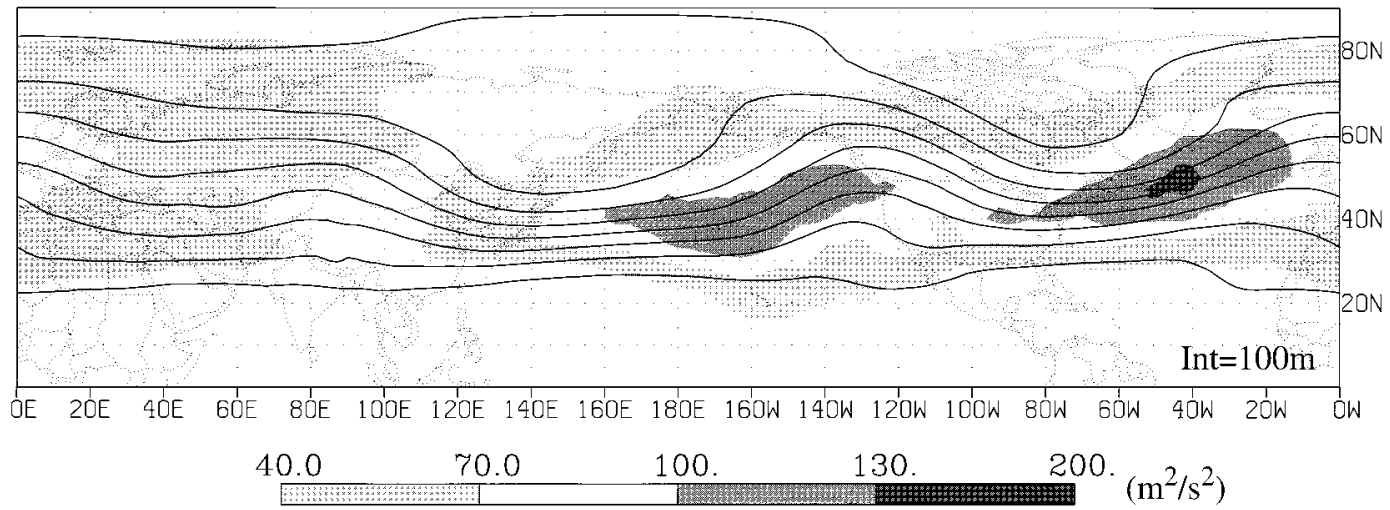

FIG. 13. Vertically averaged eddy kinetic energy and the 500-mb geopotential heights for the composite ENSO (a) warm events and (b) cold events.

\section{c. The interannual variability of sources and sink}

The 700-mb baroclinicity and 850-mb fluxes for the warm events are shown in Fig. 16, together with the differences between the warm events and the cold events. The actual distribution of baroclinicity and fluxes for the warm events (Figs. 15a,c,e) have a similar appearance to those of the November mean shown in Figs. 10a,c,e, consistent with the similar patterns observed in the eddy kinetic energy and streamfunction tendencies. However, the differences between the warm and cold events are quite revealing. A large area of enhanced baroclinicity is present in the eastern Pacific during warm events; this is highly correlated with the differences in both the heat fluxes and the variance in the meridional velocity that are both larger in the eastern Pacific for the warm events. The extra source of eastern Pacific baroclinicity by itself could explain why the seasonal deterioration of the storm track for regular winters is prevented in the case of warm events (cf. Figs. 6b and 13a).

The barotropic flow and the deformation vector for the warm and cold events (not shown) are qualitatively similar to the monthly variability displayed in Fig. 11. The similarities between these fields and those for No- vember and December confirm the observation that the shape of the storm track (elongated or deflected poleward) is highly correlated with the pattern of the deformation fields. These results strongly suggest that the winter circulation during warm events is associated with an extension of baroclinic development well into the eastern Pacific. This produces an elongated storm track which, in turn, prevents (a) the westward displacement of the trough-ridge pattern and (b) the negative feedback due to the mean flow deformation field that is characteristic of normal winters. It may be concluded that the westward or eastward shift of the EPR from average winters due to the variability of the storm track determines the strength of the PNA pattern. This nonlinear process is distinct from the formation of the PNA pattern by linear Rossby waves generated by equatorial SST anomalies.

\section{Summary and conclusions}

An analysis of 11 years of ECMWF data has been completed, focusing primarily on the vertically averaged high-frequency transients. The results support the conclusions of earlier studies and clarify some issues con- 


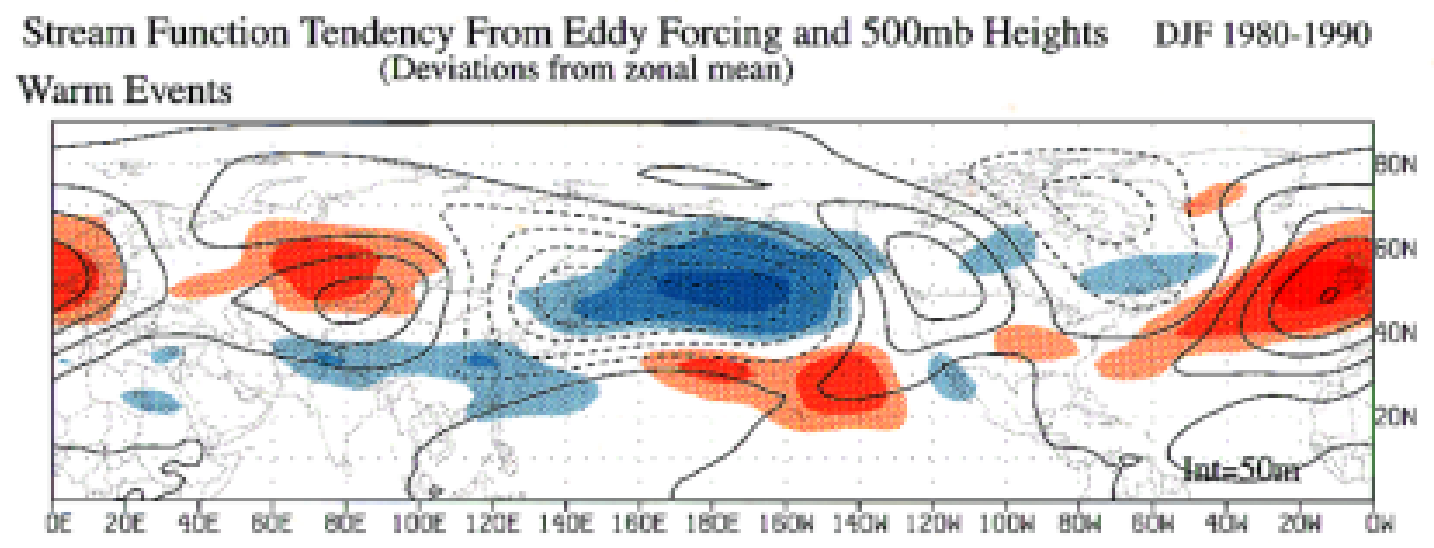

Cold Events

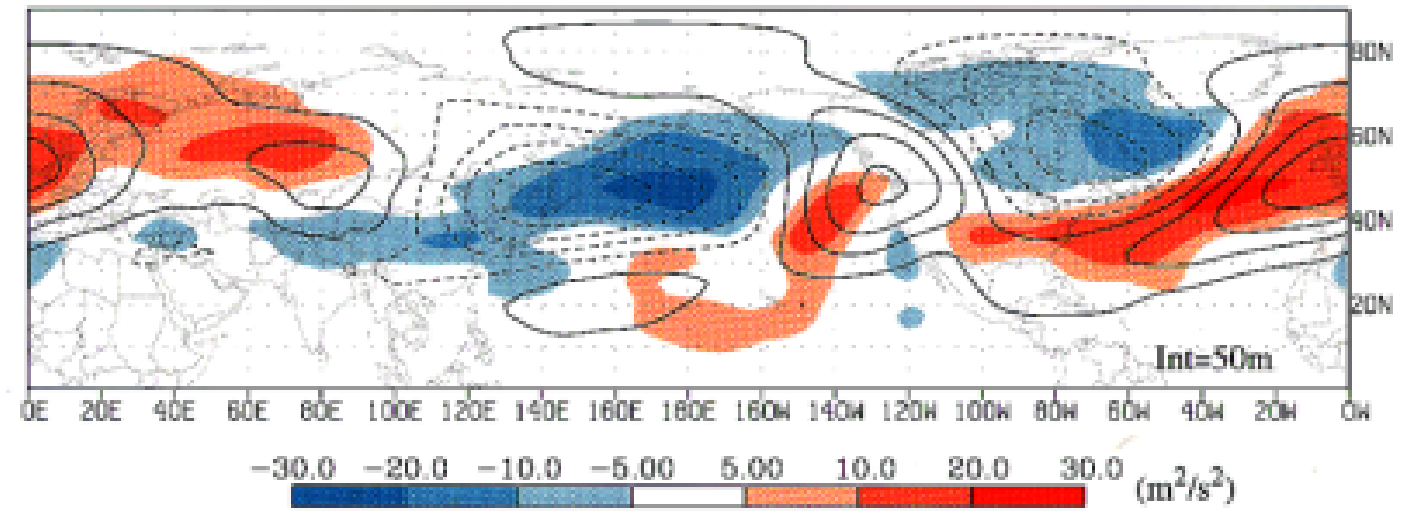

FIG. 14. Deviation of zonal mean for the streamfunction tendency and 500-mb geopotential heights for the composite ENSO (a) warm events and (b) cold events.

cerning the evolution of the wintertime circulation. The conclusions will be discussed in the context of (a) the winter storm track, (b) seasonal variability, and (c) interannual variability.

\section{a. Winter storm track}

Results show that forcing by the high-frequency (HF) eddies along both the Atlantic and Pacific storm tracks of the Northern Hemisphere is consistent with the poleward deflection of its axis and a positive feedback to the stationary circulation. Furthermore, they suggest that the forcing itself is responsible for enhancing the trough at the entrance and forcing the ridge at the termination of the storm track. The results also clarify the role of $\overline{u^{\prime} v^{\prime}}$ and $\left(\overline{v^{\prime 2}}-\overline{u^{\prime 2}}\right)$ in the column-averaged vorticity forcing. The simpler term, $\overline{u^{\prime} v^{\prime}}$ has the wellknown effect of intensifying the anticyclonic (cyclonic) tendencies on the southern (northern) side of the jet, thereby producing an increase in the barotropic component of the zonal jet. The $\left(\overline{v^{\prime 2}}-\overline{u^{\prime 2}}\right)$ term displays a quadrupole pattern that is also approximately in phase with the trough-ridge system associated with the stationary flow. Cyclonic forcing is located to the north- west and southeast of the maximum in the $\left(\overline{v^{\prime 2}}-\overline{u^{\prime 2}}\right)$ pattern, with anticyclonic forcing to the northeast and southwest, but the bulk of the cyclonic and anticyclonic forcing is found northwest and northeast of the storm track, respectively. This quadrupole effect is present only if the storm track has a localized maximum of $\overline{v^{\prime 2}}$ $\left.-\overline{u^{\prime 2}}\right)$ with more intense effects occurring with more localized maxima. It has also been shown that, in agreement with previous results, the curl of the HF eddy forcing has a spatial distribution similar to the curl of the total wind stresses over the ocean surface, but with a larger magnitude.

\section{b. Seasonal variability}

Eddy activity on the Pacific storm track has been shown to possess a seasonal life cycle, increasing during the early fall and reaching a maximum around the month of November, then decaying for most of the winter months. Month-to-month variations in eddy activity over the Pacific Ocean show that energy levels increase through November, and decrease thereafter, reaching a winter minimum at the same time that the axis of the storm track is deflected poleward and the trough-ridge 


\section{Vertically Averaged Curl of Eddy Forcing DJF1980-1990}

Warm Events

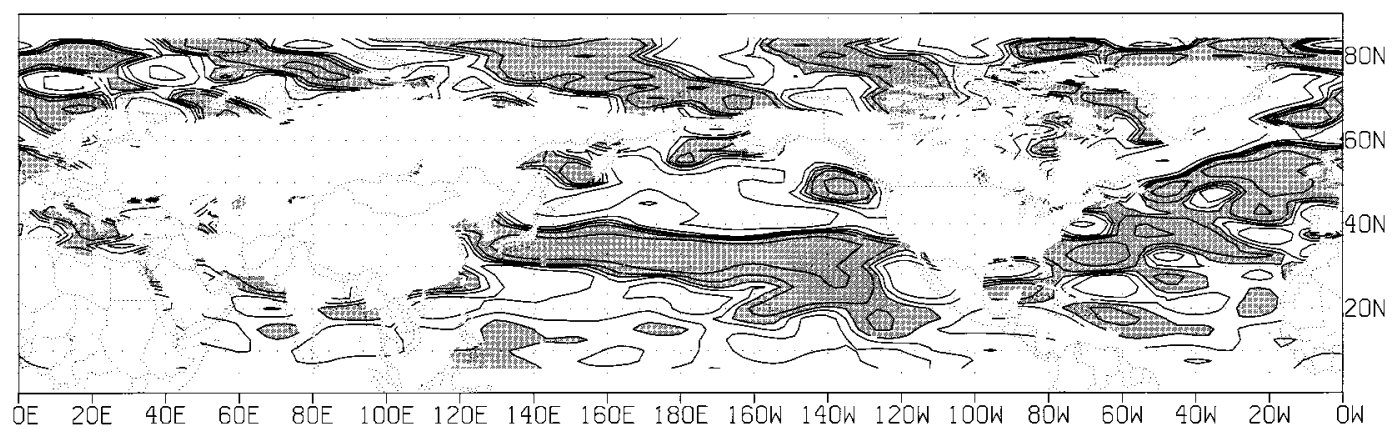

\section{Cold Events}

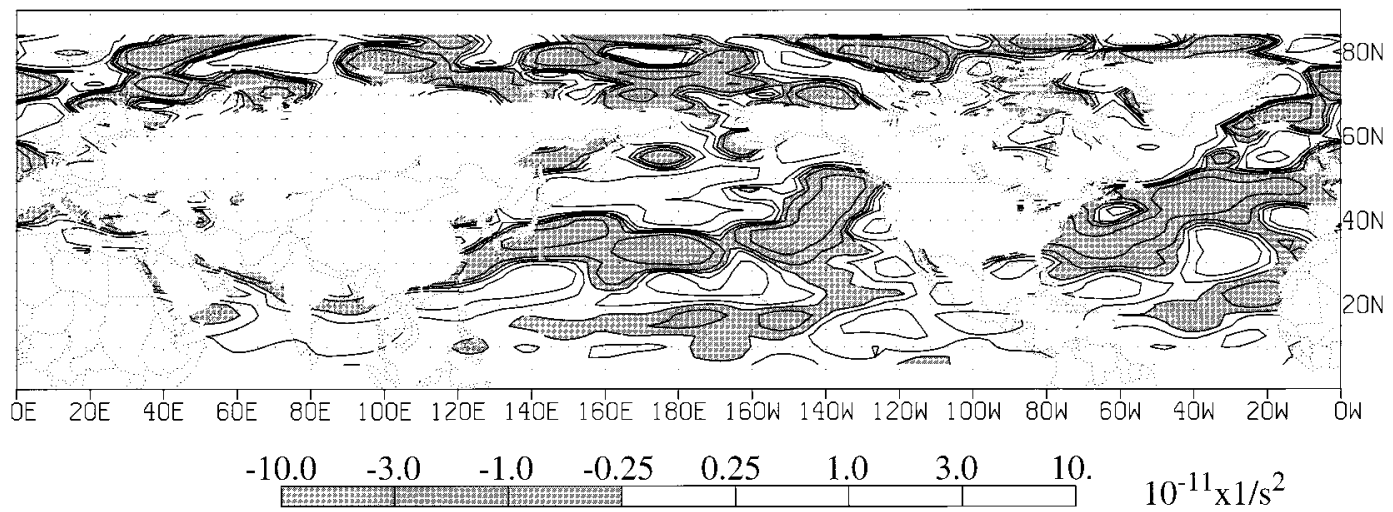

FIG. 15. Same as Fig. 5b but for the composite warm and cold ENSO events. This forcing is responsible for the streamfunction tendency shown in Fig. 14. Note the net anticyclonic forcing in the eastern Pacific during the cold events due to the poleward deflection of the storm track.

circulation pattern is intensifying. One of the more significant differences between November and December is that, in November, the storm track extends across the entire Pacific Basin, whereas in December the eddy activity terminates at roughly $140^{\circ} \mathrm{W}$. The forcing from the HF eddies shows similar differences, with the pattern in November being elongated, due mainly to $\overline{u^{\prime} v^{\prime}}$. In December, the effects of $\left(\overline{v^{\prime 2}}-\overline{u^{\prime 2}}\right)$ become more prominent, producing a trough-ridge tendency.

The transition from a fall to a winter circulation has a number of manifestations. During the fall, upper-level eddies from Asia undergo additional development when they reach the relatively warm waters of the Pacific Ocean. Although wave breaking may occur, the eddy amplitudes in the lower levels are not particularly large, and the modest amounts of energy gained via baroclinic conversion are transferred to upper levels, where it flows downstream, extending the eddy activity over the entire ocean basin. But as the jet moves southward during the transition from fall to winter, eddies are partially blocked upstream by the Tibetan Plateau. This, combined with increased low-level cooling/stabilization over the Asian landmass, results in fewer (and weaker) eddies reaching the Pacific Ocean by early winter. By December, baroclinicity in the western Pacific has increased substantially, and low-level eddies are found to break by the midocean. Upper-level eddies start to break well before reaching the west coast of North America, resulting in a displacement of the maximum in $\overline{\left(v^{\prime 2}\right.}-$ $\overline{u^{\prime 2}}$ ) westward from its November position and increasing the trough-ridge forcing by the HF eddies. This phenomenon has two negative feedbacks for eddy activity. First, the intensification of the trough in the western Pacific accelerates the barotropic zonal jet, reducing the residence time of the eddies in the baroclinic zone. Second, the intensification of the ridge in the eastern Pacific enhances the barotropic stretching deformation of the mean flow, adversely affecting the development of baroclinic eddies and making the termination of the storm track more abrupt. This negative feedback continues for the entire winter, reducing the kinetic energy of the transients. Although the Atlantic storm track has considerable larger poleward deflection and fully conforms with the arguments discussed here, the large constant seeding of waves from North America diminishes the seasonal effect observed in the Pacific storm track. 
Baroclinicity of the mean flow (700mb)
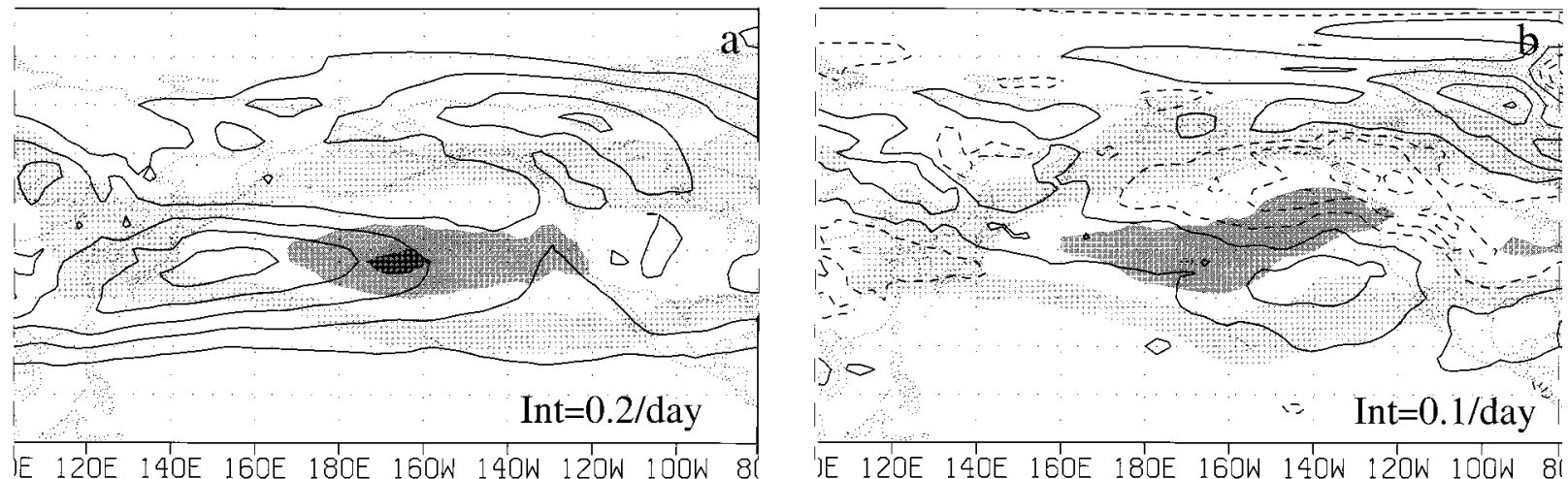

\section{Meridional heat flux t'v'(850mb)}
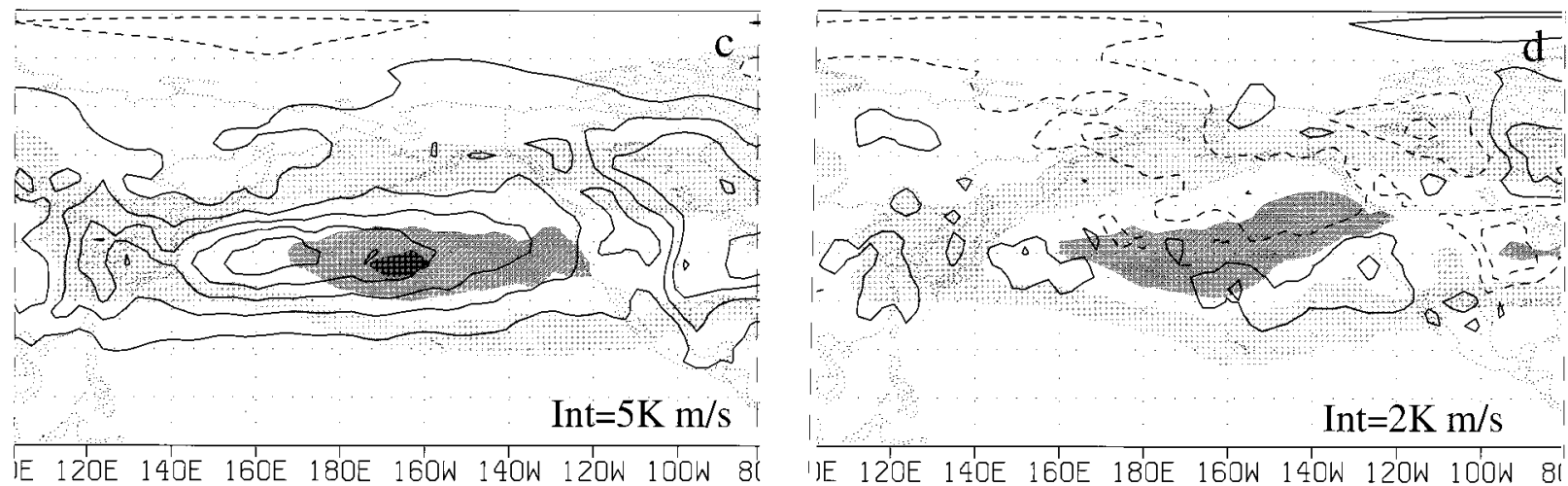

\section{Variance of meridional velocity $\mathrm{v}^{, 2}(850 \mathrm{mb})$}
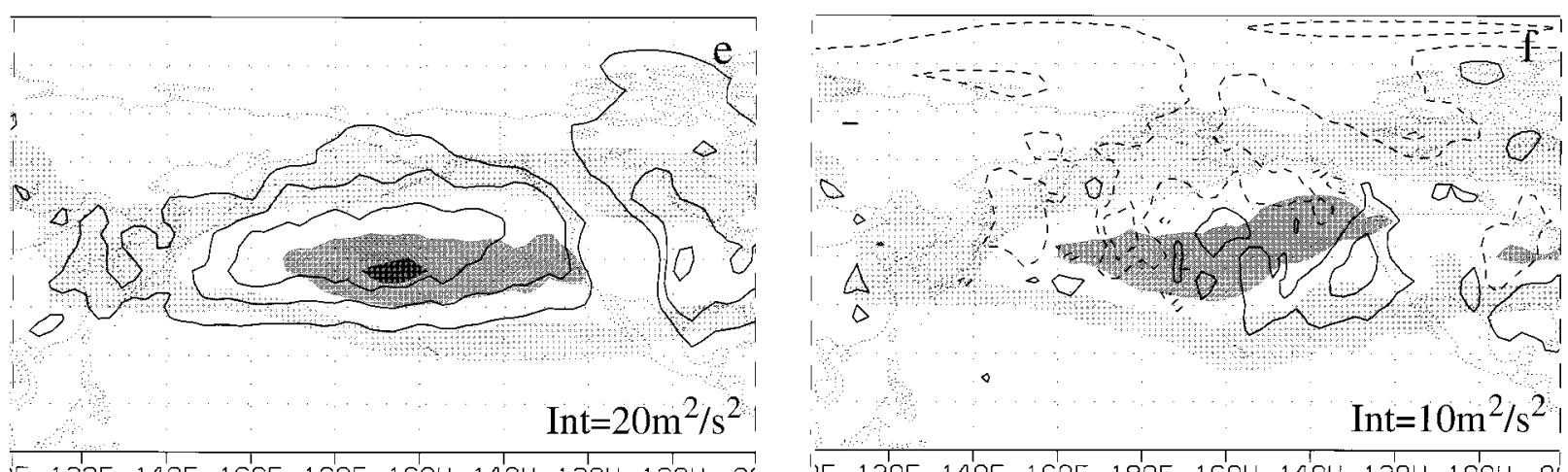

IE 120E 140E 160E 180E 160W 140W 120W 100W 8C

JE 12OE 140E 160E 180E 160W 14'OW 120W 100W 81

FIG. 16. Same as Fig. 10 but with the monthly comparison replaced by a comparison between the composite ENSO warm and cold events. Note the stronger low-level baroclinicity over the eastern Pacific during the warm events and the corresponding intensification of the eddy activity in that same region. 


\section{c. Interannual variability}

Wintertime eddy kinetic energy is seen to extend farther eastward through the Pacific Ocean during warm events, but displays an abrupt termination during cold events. Anomalies in the eddy transient forcing tend to be quite consistent with that of the height anomalies pattern itself. The extension of the storm track during the warm phase resembles that of fall conditions, and could be maintained for the entire winter because the source of low-level baroclinicity extends well into the eastern Pacific for this ENSO phase. However, it is not clear from this analysis what the source is of this enhanced baroclinicity. Whether it is a product of the warm tropical SST and colder extratropical waters in the eastern ocean, or the increase in the moisture fluxes from the Tropics, this source of baroclinicity in the eastern Pacific provides eddy energy, preventing the localization of $\left(\overline{v^{\prime 2}}-\overline{u^{\prime 2}}\right)$. Thus, the negative feedback mechanisms detrimental to eddies is inhibited during the warm events and enhanced during the cold events. From these results one may predict that the so-called midwinter suppression may not be found in years of warm events. Although the period used in this study certainly is short for a detailed seasonal variability analysis in warm and cold events, preliminary results suggest that indeed winter months in the warm cycle do not have less energy than those of the fall months. These results should be confirmed with a more extended dataset.

This study has pointed out many consistencies between the HF forcing and the time-mean circulation, but it is difficult to prove cause and effect. It is not possible to determine whether the diffluence found at the termination of the storm track is produced by the HF transients, or whether the storm track displays this pattern because the mean circulation has a difluent region there. Similarly, the possibility that Rossby waves originating in the equatorial Pacific are responsible for inhibiting ridge formation by the eddies during the warm events, or that enhanced baroclinicity in the middle of the Pacific acts to extend the storm track and prevent the formation of the east Pacific ridge, cannot be conclusively determined from this analysis. The possibility should be considered that the storm track mechanism could by itself at least enhance the observed PNA pattern observed in the ENSO cycle. A series of numerical experiments with idealized conditions is under way to help identify cause and effect. Nevertheless, the present results show that the HF transients not only play an important role in determining the stationary circulation, but by themselves could produce its decay. Finally it may be concluded that the storm tracks are not necessarily self-maintaining, but may in fact tend to produce an environment hostile to their existence, and without a constant supply of low-level baroclinicity or seeding, they decay.

Acknowledgments. I am particularly grateful to my colleagues Drs. Steve Garner and Brian Gross for their helpful comments and discussions on many topics of this study. I am especially grateful to Drs. Gabriel Lau and Isaac Held for their constructive comments that clarified some issues in this manuscript. I wish to extend my deepest appreciation to John Sheldon and Brian Gross for their editing efforts for this paper. I also wish to acknowledge Dr. Jerry Mahlman for his support of this research and to Dr. Peter Caplan and some of his colleagues at NCEP for providing the NCEP skill scores of the 5-day forecast that, although they were not presented in this paper, provided the primary motivation of the current research. Finally, a special thanks to Mr. Larry Polinsky for handling some of the ECMWF data tapes and to the members of the GFDL Computer Operation Support, whose effort was so much appreciated.

APPENDIX

\section{High-Frequency Filter}

Time filters that separate the slowly varying scales from the more synoptic timescales have been used in many studies (e.g., Blackmon et al. 1977; Lau and Holopainen 1984). More recently, Chang (1993) pointed out that the high-frequency selection for the filter could affect the interpretation of the signal in a study of the downstream characteristics of eddies in the Pacific storm track. He found that a time filter with a half-power point of 12 days retains most of the characteristics of highfrequency eddies, whereas a filter with a 6-day halfpower point could significantly distort the signal. The current study employs a 41-point high-pass filter with half-power points around 12 and 6 days as in Chang (1993)(see his Table A1 for the numerical values of the coefficients).

Both filters were tested and it was decided that, given that its main use would be to evaluate the role of highfrequency transients in the time-mean flow in general and the forcing of the eastern Pacific ridge in particular, the 12-day filter introduced less distortion. A comparison of the time lag regression of the meridional velocity for the nonfiltered data and the 12- and 6-day filters at longitudes near the wintertime eastern Pacific ridge was performed and the horizontal scales for the 6- and 12day filtered data were found to be very similar. But, in a result similar to that found by Chang (1993), the propagation characteristics are quite distorted for the 6-day filter. When the zonal speed of synoptic-scale disturbances drops in the vicinity of the ridge, they will appear to have timescales longer than those found over regions of strong advection, and the 6-day filter may prove less accurate in representing the intensity of these systems. It should be noted that while downstream propagation was found for the unfiltered and 12-day filter regressions, the 6-day filter regression showed a clear upstream propagation. The effect could be, as previously discussed, the result of the filter distortion (Chang 


\section{Stram Function Tendency from Eddy Forcing DEC 1980-1990}
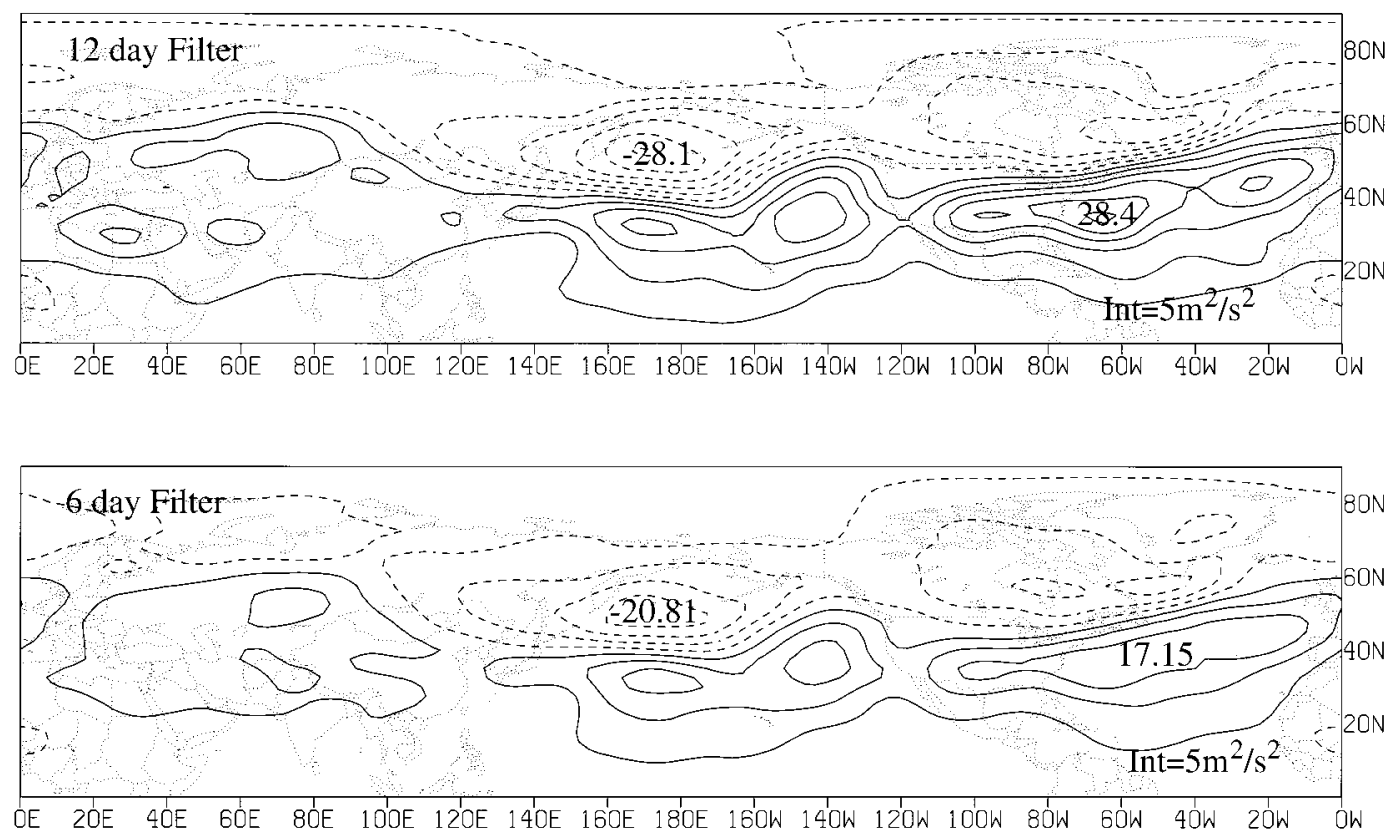

FIG. A1. Comparison of the streamfunction tendency from the vertically averaged transient forcing of (a) for the 12-day half-power time filter and (b) for the 6-day half-power time filter

1993). However, unfiltered regressions with zonal wavelet analysis have also shown an upstream propagation for the shorter waves. It seems that these shorter waves in the blocking region are more a product of large-scale wavebreaking than synoptic waves. These results are still under investigation.

The streamfunction tendency for winter conditions (December-February) from 1980-90 for both the 12day (a) and 6-day (b) half-power point filter is shown in Fig. A1, in a manner analogous to Fig. 1b. Despite a considerable degree of similarity between them, the data obtained with the 12-day filter possess propagation characteristics more similar to the unfiltered time series.

\section{REFERENCES}

Blackmon, M. L, J. M. Wallace, N.-C. Lau, and S. L. Mullen, 1977: An observational study of the Northern Hemisphere wintertime circulation. J. Atmos. Sci., 34, 1040-1053.

- , Y. H. Lee, and J. M. Wallace, 1984: Horizontal structure of $500 \mathrm{mb}$ height fluctuations with long, intermediate and short time scales. J. Atmos. Sci., 41, 961-979.

Branstator, G., 1995: Organization of stormtrack anomalies by recurring low-frequency circulation anomalies. J. Atmos. Sci., 52, 207-226.

Chang, E. K. M., 1993: Downstream development of baroclinic waves as inferred from regression analysis. J. Atmos. Sci., 50, 20382053.

—, and I. Orlanski, 1993: On the dynamics of a storm track. $J$. Atmos. Sci., 50, 999-1015.

Emanuel, K. A., M. Fantini, and A. J. Thorpe, 1987: Baroclinic instability in an environment of small stability to slantwise moist convection. Part I: Two-dimensional models. J. Atmos. Sci., 44, $1559-1573$.
Held, I. M., S. W. Lyons, and S. Nigam, 1989: Transients and the extratropical response to El Niño. J. Atmos. Sci., 46, 163-174.

Holopainen, E. O., and A. H. Oort, 1981a: Mean surface stress curl over the oceans as determined from the vorticity budget of the atmosphere. J. Atmos. Sci., 38, 262-269.

_ , and - 1981b: On the role of large-scale transient eddies in the maintenance of the vorticity and enstrophy of the time-mean atmospheric flow. J. Atmos. Sci., 38, 270-280.

-, L. Rontu, and N.-C. Lau, 1982: The effect of large-scale transient eddies on the time-mean flow in the atmosphere. J. Atmos. Sci., 39, 1972-1984.

Holton, J. R., 1992: An Introduction to Dynamical Meteorology. Academic Press, 509 pp.

Horel, J., and J. Wallace, 1981: Planetary-scale atmospheric phenomena associated with the Southern Oscillation. Mon. Wea. Rev., 109, 813-829.

Hoskins, B. J., 1983: Theory of transient eddies. Large-Scale Dynamical Processes, B. H. Hoskins and R. P. Pearce, Eds., Academic Press.

— Atmosphere. Academic Press, 397 pp.

- and P. J. Valdes, 1990: On the existence of storm-tracks. $J$. Atmos. Sci., 47, 1854-1864.

_ I. N. James, and G. H. White, 1983: The shape, propagation and mean-flow interaction of large-scale weather systems. $J$. Atmos. Sci., 40, 1595-1612.

Illari, L., 1984: Diagnostic study of the potential vorticity in a warm blocking anticyclone. J. Atmos. Sci., 41, 3518-3526.

- and J. C. Marshall, 1983: On the interpretation of eddy fluxes during a blocking episode. J. Atmos. Sci., 40, 2232-2242.

James, I. N., 1987: Suppression of baroclinic instability in horizontally sheared flows. J. Atmos. Sci., 44, 3710-3720.

Lau, N.-C., 1979: The observed structure of tropospheric stationary waves and the local balances of vorticity and heat. J. Atmos. Sci., 36, 996-1016.

, 1985: Modeling the seasonal dependence of the atmospheric response to observed El Niños in 1962-76. Mon. Wea. Rev., 113, 1970-1996. 
_ 1988: Variability of the observed midlatitude storm tracks in relation to low frequency changes in circulation pattern. J. Atmos. Sci., 45, 2718-2743.

— time-mean flow as identified by geopotential tendencies. $J$. Atmos. Sci., 41, 313-328.

— tropic transient eddy forcing associated with monthly changes in the midlatitude storm tracks. J. Atmos. Sci., 48, 2589-2613.

Mak, M., and M. Cai, 1989: Local barotropic instability. J. Atmos. Sci., 46, 3289-3311.

Nakamura, H., 1992: Midwinter suppression of baroclinic wave activity in the Pacific. J. Atmos. Sci., 49, 1629-1642.

Opsteegh, J. D., and A. D. Vernekar, 1982: A simulation of the January standing wave pattern including the effects of transient eddies. J. Atmos. Sci., 39, 734-744.
Orlanski, I., J. Katzfey, C. Menendez, and M. Marino, 1991: Simulation of an extratropical cyclone in the Southern Hemisphere: Model sensitivity. J. Atmos. Sci., 48, 2293-2311.

Shutts, G. J., 1983: The propagation of eddies in diffluent jetstreams: Eddy vorticity forcing of "blocking" flow fields. Quart. J. Roy. Meteor. Soc., 109, 737-761.

Simmons, A. J., and B. J. Hoskins, 1976: Baroclinic instability on the sphere: Normal modes of the primitive and quasi-geostrophic equations. J. Atmos. Sci., 33, 1454-1477.

Trenberth, K. E., 1991: Storm tracks in the Southern Hemisphere. $J$. Atmos. Sci., 48, 2159-2178.

—, J. Olson, and W. Large, 1989: A global ocean wind stress climatology based on ECMWF analysis. NCAR Tech. Note NCAR/TN-338+STR, 93 pp.

Whitaker, J. S., and R. M. Dole, 1995: Organization of storm tracks in zonally varying flows. J. Atmos. Sci., 52, 1178-1191. 